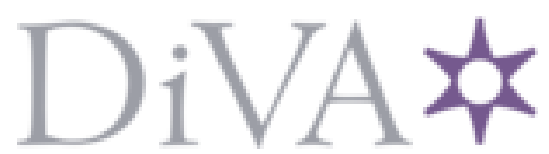

http://www.diva-portal.org

\title{
Postprint
}

This is the accepted version of a paper published in Vehicle System Dynamics. This paper has been peer-reviewed but does not include the final publisher proof-corrections or journal pagination.

Citation for the original published paper (version of record):

Wanner, D., Drugge, L., Stensson Trigell, A. (2014)

Fault classification method for the driving safety of electrified vehicles.

Vehicle System Dynamics

http://dx.doi.org/10.1080/00423114.2014.889317

Access to the published version may require subscription.

N.B. When citing this work, cite the original published paper.

Permanent link to this version:

http://urn.kb.se/resolve?urn=urn:nbn:se:kth:diva-131222 


\title{
RESEARCH ARTICLE
}

\section{Fault classification method for the driving safety of electrified vehicles}

\author{
Daniel Wanner, ${ }^{a *}$ Lars Drugge $^{\mathrm{a}}$ and Annika Stensson Trigell ${ }^{\mathrm{a}}$ \\ ${ }^{a}$ KTH Royal Institute of Technology, School of Engineering Sciences, Department of \\ Aeronautical and Vehicle Engineering, SE-100 44 Stockholm, Sweden
}

(Submitted for publication in September 2013)

\begin{abstract}
A fault classification method is proposed which has been applied to an electric vehicle. Potential faults in the different subsystems that can affect the vehicle directional stability were collected in a failure mode and effect analysis. Similar driveline faults were grouped together if they resembled each other with respect to their influence on the vehicle dynamic behaviour. The faults were physically modelled in a simulation environment before they were induced in a detailed vehicle model under normal driving conditions. A special focus was placed on faults in the driveline of electric vehicles employing in-wheel motors of the permanent magnet type. Several failures caused by mechanical and other faults were analysed as well. The fault classification method consists of a controllability ranking developed according to the functional safety standard ISO 26262. The controllability of a fault was determined with three parameters covering the influence of the longitudinal, lateral and yaw motion of the vehicle. The simulation results were analysed and the faults were classified according to their controllability using the proposed method. It was shown that the controllability decreased specifically with increasing lateral acceleration and increasing speed. The results for the electric driveline faults show that this trend cannot be generalised for all the faults, as the controllability deteriorated for some faults during manoeuvres with low lateral acceleration and low speed. The proposed method is generic and can be applied to various other types of road vehicles and faults.
\end{abstract}

Keywords: Vehicle safety, vehicle dynamics, fault analysis, fault classification, electric vehicles, ISO 26262.

\section{Nomenclature}

$a_{x} \quad$ Vehicle longitudinal acceleration at the centre of gravity (CG).

$a_{y} \quad$ Lateral vehicle acceleration at the CG.

$c_{i} \quad$ Spring stiffness of the $i^{\text {th }}$ corner.

$f_{x, i} \quad$ Longitudinal force of the $i^{\text {th }}$ tyre.

$f_{y, i} \quad$ Lateral force of the $i^{\text {th }}$ tyre.

$h$ Height of the CG from the ground.

$i_{t} \quad$ Ratio between the tyre and the electrical machine.

$i_{g} \quad$ Transmission ratio of planetary gear box.

$l_{f} \quad$ Distance of the CG to the front axle.

$l_{r} \quad$ Distance of the CG to the rear axle.

$p \quad$ Tyre pressure.

$r_{\text {dyn }}$ Dynamic tyre rolling radius.

$s_{f} \quad$ Front track width.

$s_{r} \quad$ Rear track width.

$t \quad$ Simulation time.

$t_{f} \quad$ Time of fault induction.

*Corresponding author. Email: dwanner@kth.se 
$t_{r} \quad$ Reaction time.

$v_{x} \quad$ Longitudinal vehicle velocity at the CG.

$C_{j} \quad$ Controllability class with $\mathrm{j}=0,1,2,3$.

$E_{j} \quad$ Exposure class with $\mathrm{j}=0,1,2,3,4$.

$I_{x x} \quad$ Body roll moment of inertia.

$I_{y y} \quad$ Body pitch moment of inertia.

$I_{z z} \quad$ Body yaw moment of inertia.

$\mathrm{K}_{c} \quad$ Correction factor of the simplified torque model.

$\mathrm{K}_{\bar{T}} \quad$ Mean value of the simplified torque model.

$\mathrm{K}_{|T|} \quad$ Amplitude of the simplified torque model.

$Q_{f} \quad$ Fault influence index.

$Q_{x} \quad$ Collision avoidance index.

$Q_{y} \quad$ Lane keeping index.

$Q_{z} \quad$ Vehicle stability index.

$Q_{i}^{*} \quad$ Fault classification with the respective indices $\mathrm{i}=\mathrm{x}, \mathrm{y}, \mathrm{z}$.

$S_{j} \quad$ Severity class with $\mathrm{j}=0,1,2,3$.

$T_{d} \quad$ Desired traction torque.

$T_{F} \quad$ Faulty traction torque.

$\lambda_{C x} \quad$ Scaling factor (SF) for the longitudinal tyre stiffness.

$\lambda_{C y} \quad \mathrm{SF}$ for the lateral tyre stiffness.

$\lambda_{C(p)} \quad \mathrm{SF}$ for the pressure-dependent longitudinal tyre stiffness.

$\lambda_{K x \kappa} \quad$ SF the for brake slip.

$\lambda_{K y \alpha} \quad \mathrm{SF}$ the for cornering stiffness.

$\lambda_{p} \quad$ SF for the pressure-dependent lateral tyre stiffness.

$\lambda_{\mu x} \quad$ SF for the longitudinal peak friction coefficient.

$\lambda_{\mu y} \quad$ SF for the lateral peak friction coefficient.

$\dot{\psi}_{m} \quad$ Mean yaw velocity

$\ddot{\psi}_{f, m} \quad$ Mean yaw acceleration of the faulty vehicle state.

$\Delta \quad$ Any difference.

\section{Introduction}

Electrification in chassis and driveline systems within the automotive domain has increased extensively in recent years. Potential improvements of passenger safety, comfort and handling can be achieved by the extended functionalities of electrified chassis systems and active safety systems. The introduction of electronic stability control systems (ESC) has improved passenger safety considerably. Their potential has been highlighted in recent studies, showing that vehicles equipped with ESC reduce fatal single-vehicle accidents by $50 \%$ [1, 2]. New solutions for driveline systems resulting from governmental incentives, the current research foci of vehicle manufacturers, a shortage of natural resources and legal requirements concerning emissions will lead to a broad rise in the number of hybrid electric and electric vehicles $(\mathrm{EV})$ in the coming decades $[3-5]$. All of these developments are enhancing the variety of functions for vehicle directional control and thus the flexibility of vehicle behaviour.

The coming rise in the use of electric and electronic (E/E) components and subsystems in vehicles will entail an increase in complexity, and thus the probability of faulty vehicles will become higher in the future vehicle generation [6]. A new type of vehicular system is appearing with the increase in EVs comprising E/E components and subsystems. Since there is little experience of failures in electric vehicles at present, the research work presented in this article focuses on vehicles with an electric driveline.

More recalls by vehicle manufacturers due to such problems can be observed. For example, together with Bosch, Daimler developed an electro-hydraulic brake system called Sensotronic Brake Control. The system's high frequency dynamics and precise sensor-supported control improve the braking distance and cooperate 
with other electronic safety systems in the car, such as the ESC, to enhance vehicle safety [7, 8]. However, the software of the system failed during driving, resulting in a longer stopping distance and the necessity of additional brake-pedal effort on the part of the driver, and entailing a recall. More than 1.3 million vehicles were affected by that recall [9]. The high complexity of the manufacturing process of these new systems is also shown in two kinds of hybrid vehicles made by Toyota. In this example, transistors that are used in certain inverters of these two types of hybrid vehicles had bad soldering spots. The heat development caused by large current flow during high-load driving could damage the solder spot and cause a breakdown of the vehicle [10]. Therefore, the vehicles were recalled by Toyota.

Apart from recalls due to E/E systems, purely mechanical recalls are still common as well. For example, Nissan had to recall a specific model because the power steering rack bolts were not tightened according to the specification [11. This fault might have led to a total loss of lateral vehicle control. Recalls by car manufacturers are becoming increasingly problematic, as new systems are being installed in a large amount of vehicles, and therefore a recall becomes expensive, not to mention the negative effects on the manufacturer's reputation for high quality. If these faults develop into a vehicle failure during normal operation, they can lead to an accident. Therefore, high system dependability is needed to minimise the risks, and fulfil the most important requirements such as active and passive safety, dynamic driving performance, driving dynamics and excellent handling, as well as driving comfort.

A study on three simple failure modes in an electric vehicle with individual propelling torque on each wheel was performed by Euchler et al. [12, 13]. A maximum positive and negative propelling torque, as well as no torque at the wheel with three different friction levels, was analysed. It was concluded that critical situations occur mainly during low friction levels or high lateral accelerations.

High vehicle safety can be achieved and the vehicle control can unfold its full potential, if the faults that influence vehicle stability are detected and isolated, and can be classified according to their controllability 1. This is useful information that can be exploited within fault-tolerant vehicle control, which also enables vehicle engineers to find potentially critical faults.

The aim of the research study presented in this article was to classify faults according to their controllability for vehicle stability. The classification method of the study is generic, and thus applicable to other road vehicles and faults. The analysis is constrained to one set of vehicle parameters and the analysed faults. In Section 2, an overview of the proposed methodology for fault classification is given. Section 3 describes how the various faults were collected and merged to form distinct fault groups. The fault group models, as well as the applied vehicle model, are explained in Section 4. In Section 5, the selected driving manoeuvres are presented and explained, before the fault classification method, with its controllability ranking according to the functional safety standard ISO 26262, is described in Section 6. The results and their analysis are presented in Section 7. Concluding remarks and recommendations for further research are given in Section 8.

\footnotetext{
${ }^{1}$ Controllability is a measure of the extent to which the driver is able to control the vehicle. Normal driving conditions are fully controllable, while a puncture is less controllable for the driver. Controllability is defined in ISO 26262 .
} 


\section{Methodology}

The main focus of this study has been placed on electric and hybrid electric vehicles (EV). An EV with four in-wheel motors has been investigated. Its vehicle specifications can be found in Section 4.1.

Besides the focus on faults inside the electric driveline, mechanical and hydraulic faults have also been analysed in this study. Mechanical and hydraulic faults can also occur in normal cars with an internal combustion engine only, and therefore this study can be considered valid for conventional vehicles as well. An extensive failure mode analysis was carried out for the electric driveline, i.e. the permanent magnet synchronous machine, inverter, battery and low voltage wiring. The conventional subsystems considered for this analysis which can have an influence on the vehicle behaviour are the tyre, wheel rim, wheel hub, planetary gear, suspension, brake and steering system, as well as the software control. Possible faults in the different subsystems were collected. For the electric driveline, this was extended with a more detailed failure mode and effect analysis. Due to the high complexity of the electric driveline, faults which were highly likely to lead to vehicle failures with high severity for the vehicle stability were prioritised during the modelling phase. The large number of collected faults provided a good reason for merging them to form fault groups (FG). Each fault group contains those collected faults which act in a similar way on the vehicle behaviour. The fault groups were modelled in Matlab/Simulink and co-simulated with a high-fidelity vehicle model in IPG CarMaker.

The focus of the fault evaluation was placed on vehicle safety, and therefore the severity of the faults' influence on the level of controllability of the vehicle was analysed by comparing a faulty with a healthy vehicle state. Based on these results, a methodology for ranking the faults was developed. This fault ranking gave direct information about which faults were severe and affected the vehicle directional stability. The ranking results were then placed into four different controllability classes, from easy to control, $C_{0}$, to uncontrollable, $C_{3}$, according to ISO 26262. This information can be used in the fault-tolerant control of the vehicle in order to compensate for faults that lead to vehicle failures, and thus increase vehicle safety. Further, the information can be considered during the design phase of a vehicle. A scheme of the proposed methodology is depicted in Fig. 1.

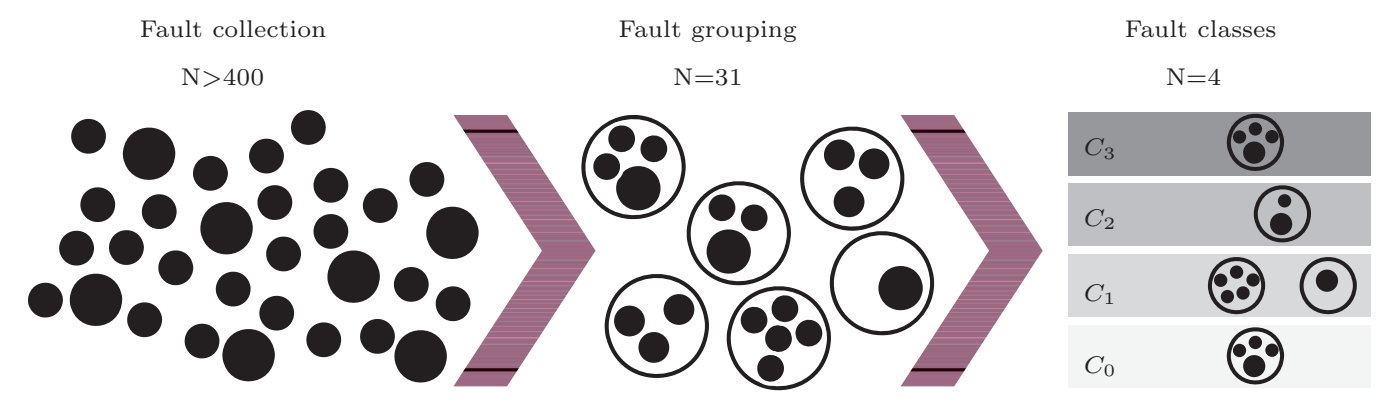

Figure 1. General scheme of the fault classification.

This research study was constrained by the fact that not all the faults occurring during normal driving operation could be covered. Therefore, the goal was to achieve a reasonable coverage of both the most common and the most extreme cases. Further, the results of the study are only valid for the analysed set of vehicle parameters. 


\section{Fault collection and grouping}

Before describing the fault collection and grouping, definitions of terms according to the IFAC SAFEPROCESS [14] will now be provided in this section. The SAFEPROCESS Technical Committee defines a fault as an "unpermitted deviation of at least one characteristic property or parameter of the system from the ... standard condition". The fault can then lead to a malfunction or a failure. A malfunction is defined as an "intermittent irregularity in the fulfilment of a system's desired function", and thus a degradation of the system's performance. If a failure occurs in components or a subsystem, the system will fail. A failure is defined as a "permanent interruption of a system's ability to perform a required function under specified operating conditions". The definition of the system boundaries determines the terminology as well. Considering the tyre as a system, a loss of air may be a failure. If the vehicle is considered as the system, a punctured tyre may be a fault leading to the failure of the vehicle. The latter boundary definition was considered in this research. A global fault collection was conducted to cover as many faults as possible that could lead to a failure or a malfunction in a passenger car.

This fault collection was carried out by studying each subsystem from the tyre contact patch, via the different subsystems for vehicle directional control, to the software control of the vehicle. The collected faults were then merged into fault groups (FG) depending on their influence on the vehicle behaviour. Faults with little or no distinction between them regarding their influence on the vehicle behaviour were subsumed under the same fault group. Even though some fault groups were based on purely mechanical or hydraulic faults, the main focus was placed on faults of the electric driveline. This decision is supported by the findings in [6] that two thirds of all vehicle breakdowns are of an electric nature. Faults of E/E components that lead to vehicle failures or malfunctions appear in general more randomly than mechanical or hydraulic faults. Software faults are, however, more systematic, as errors produced in the development phase are not uncommon. These faults can appear in different forms, both locally and globally. All the fault groups are listed in the Appendix.

The fault groups FG1 - FG5 focus on the fault characteristics of the electric driveline. The studied in-wheel motors are outer-rotor synchronous machines of the permanent magnet type. Due to the constant excitation provided from the permanent magnets in the rotor, the fault characteristics of permanent magnet motors differ from those of conventional induction motors [15 17]. A fault analysis was conducted in [18] to specify the severity of different faults in the electric driveline of an electric vehicle. Based on the results in [17 21], the following severe fault conditions were analysed, as these result in high changes in the torque characteristics: a three-phase balanced short circuit, an inverter shutdown, a single-transistor turn-on failure1, a current sensor misalignment and a controller fault.

The three-phase balanced short circuit can occur due to bad isolation of the windings inside the connection box or inside the electric motor and was subsumed under FG1. The gate signals for the power transistor devices vanish with an inverter shutdown, which can be initiated by the protection circuit of the inverter in the event of an over-current or over-temperature condition. This fault condition originates from a failure of the gate drive (supplying the gate pulses to the power transistors), a signal-cable breakdown or a loss of power to the control circuit. If the fault occurs in the field-weakening range, a speed-dependent braking torque

\footnotetext{
${ }^{1}$ The system boundaries include the transistor only, and therefore the name single-transistor turn-on failure is valid. This name was established within the domain of electrical engineering, and has therefore been kept the same.
} 
is supplied. Below the nominal working point, no torque is supplied, on the other hand. This fault was classified under FG2. Another fault in an inverter leading to less drastic changes is the single-transistor turn-on failure, which was classified under FG3. In addition to the electrical machine and the inverter, other components utilised to control the electric driveline can fail during operation. A current sensor misalignment, for instance, can lead to wrong information being given to the driveline control and cause a failing driveline. The current sensor measures at least two of the three phase currents, and its measurements are then used to control the system. FG4 comprises the current sensor misalignment. A controller fault can lead to the controller failing to deliver the correct control signal, such as the maximum propelling torque, requested of the electric machine. This fault falls under FG5.

All the other fault groups in this study subsume mechanical and hydraulic faults as well as external disturbances. FG6 includes typical tyre punctures, while FG7 comprises deterioration of the tyre cornering stiffness. FG8 and FG9 concern extreme cases where either a wheel is blocked or a wheel becomes loose and falls off. Both cases can occur due to various fault possibilities. Vibrations and brake torques due to misalignment of the rim, a broken wheel hub bearing, material fatigue, etc. were collected in FG10, FG11 and FG12. A wheel detached from the driveline was classified under FG13. Steering system failures were included in FG14 and FG23 through FG26, which comprise several of the possible mechanical, hydraulic and software-related faults. All the faults related to the suspension system, such as a sudden change in the ride height in an active system, were collected in FG15 and FG16, as well as FG27 through FG31; FG27 - FG31 also comprise in passive suspension systems. FG17 through FG20 comprise faults that occur externally or in the tyre, such as varying friction coefficients or weak tyre side walls. Brake system faults, leading to a different brake torque from that expected, were classified under FG21 and FG22. A full list of the fault groups is to be found in the Appendix.

In this study, a selection of fault groups has been analysed. The focus has been placed on the electric driveline and the fault groups associated with the tyre contact patch. Table 1 presents the selected fault groups and their failure effects, with examples provided for each group.

Table 1. Faults selected for the analysis

\begin{tabular}{|c|c|c|c|}
\hline Fault group & Fault description & Failure effect & Example \\
\hline FG1 & Fault in electrical machine & Negative $f_{x, i}$ & $\begin{array}{l}\text { three-phase } \\
\text { balanced short } \\
\text { circuit }\end{array}$ \\
\hline FG2 & Fault in power electronics & Negative $f_{x, i}$ & $\begin{array}{l}\text { Inverter shutdown } \\
\text { (field-weakening) }\end{array}$ \\
\hline FG3 & $\begin{array}{c}\text { Inverter delivers wrong } \\
\text { currents }\end{array}$ & Negative $f_{x, i}$ & $\begin{array}{l}\text { Single-transistor } \\
\text { turn-on failure }\end{array}$ \\
\hline FG4 & $\begin{array}{l}\text { Current sensor error gives } \\
\text { wrong signal to motor control }\end{array}$ & Negative $f_{x, i}$ & $\begin{array}{l}\text { Current sensor } \\
\text { misalignment }\end{array}$ \\
\hline FG5 & Maximum traction torque & Increased $f_{x, i}$ & $\begin{array}{l}\text { Failure in motor } \\
\text { control }\end{array}$ \\
\hline FG6 & Pressure reduction in tyre & $\begin{array}{l}\text { Reduction in } f_{x, i}, f_{y, i} \\
C_{x} \text { and } C_{y}\end{array}$ & Puncture \\
\hline FG7 & $\begin{array}{c}\text { Large decrease in friction } \\
\text { coeff. } \mu\end{array}$ & $\begin{array}{l}\text { Large reduction in } f_{x, i} \\
\text { and } f_{y, i}\end{array}$ & Icy road \\
\hline FG8 & Blocked wheel(s) & $\begin{array}{c}\text { Maximum negative } \\
f_{x, i}\end{array}$ & Gear box failure \\
\hline
\end{tabular}




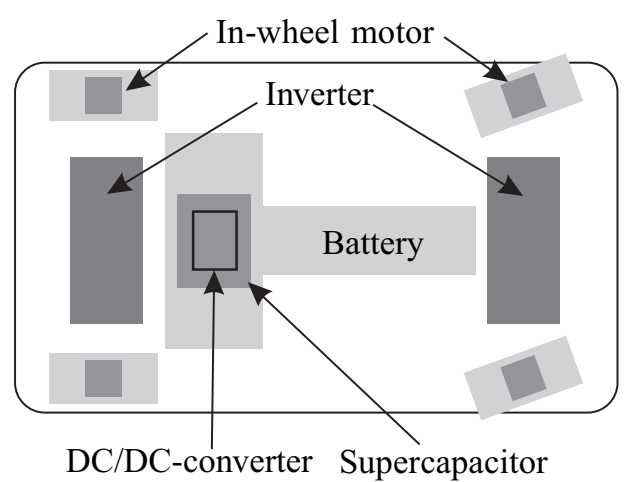

Figure 2. Schematic view of the vehicle configuration.

\section{Vehicle model and fault group models}

\subsection{Vehicle specifications}

The vehicle specifications were based on a medium-sized vehicle of the sedan type. The driveline of the vehicle was assumed to be all-electric and to be propelled by four in-wheel motors with a continuous power of $15 \mathrm{~kW}$ and a rated torque of $170 \mathrm{Nm}$. Apart from the electric driveline, the parameters of the vehicle resemble those of a typical passenger car. The electric driveline configuration is shown in Fig. 2. The energy storage consists of a lithium-ion battery pack and a supercapacitor. The latter is connected to the DC-link via a DC/DC-converter and works as a transient buffer. The limitations of the battery pack during fast energy transfer are compensated for by the supercapacitor with its faster charge and discharge characteristics. The energy storage is mounted on the body floor and is included in the mass of the vehicle. The absence of a combustion engine and the location of the energy storage unit result in the weight distribution shifted rearwards compared to that of a conventional car. Four separate inverters control the power flow from and to each in-wheel motor. All four wheels accommodate an in-wheel motor with a planetary gear transmission. The in-wheel motors propelling and partly braking the analysed vehicle are permanent magnet synchronous machines (PMSM) with an outer-rotor design specifically created for vehicle features, such as a certain speed-torque curve, reduced torque ripple and light-weight characteristics. In addition, the chassis was assumed to have standard components such as friction brakes, passive steering and a passive suspension system. The basic vehicle parameters of these systems are listed in Table 2 and they were derived from measurements of a similar type of vehicle. Linear springs and anti-roll bar coefficients as well as non-linear damper characteristics were applied, see Fig. 3. For some of the faults, some subsystems of the vehicle configuration were extended, e.g. for faults in the suspension system, an active system was assumed for FG15 and FG16.

\subsection{Vehicle model}

The applied vehicle model is a high-fidelity vehicle dynamics model employing a Magic Formula tyre model with combined slip according to [22]. It was designed in a co-simulation environment with IPG CarMaker and Matlab/Simulink, which gave access to variables for the fault implementation. The vehicle parameters, driving manoeuvres and road settings can be adjusted in the IPG CarMaker GUI, while adjustments in the vehicle dynamics model itself (and thus the implementation of the considered fault groups) are performed in the Matlab/Simulink environment. 
Table 2. Electric vehicle parameters.

\begin{tabular}{lll}
\hline Parameter & Symbol & Value \\
\hline Vehicle mass & $m$ & $1540 \mathrm{~kg}$ \\
Body roll moment of inertia & $I_{x x}$ & $542 \mathrm{kgm}^{2}$ \\
Body pitch moment of inertia & $I_{y y}$ & $2480 \mathrm{kgm}^{2}$ \\
Body yaw moment of inertia & $I_{z z}$ & $2656 \mathrm{kgm}^{2}$ \\
Distance from the CG to the front axle & $l_{f}$ & $1.38 \mathrm{~m}$ \\
Distance from the CG to the rear axle & $l_{r}$ & $1.27 \mathrm{~m}$ \\
Front track width & $s_{f}$ & $1.54 \mathrm{~m}$ \\
Rear track width & $s_{r}$ & $1.53 \mathrm{~m}$ \\
Height of the CG from the ground & $h$ & $0.54 \mathrm{~m}$ \\
Dynamic tyre roll radius & $r_{\text {dyn }}$ & $0.30 \mathrm{~m}$ \\
Front spring stiffness & $c_{1}, c_{2}$ & $33 \mathrm{kN} / \mathrm{m}$ \\
Rear spring stiffness & $c_{3}, c_{4}$ & $56 \mathrm{kN} / \mathrm{m}$ \\
Front anti-roll bar stiffness & $c_{12}$ & $20006 \mathrm{~N} / \mathrm{m}$ \\
Rear anti-roll bar stiffness & $c_{34}$ & $16088 \mathrm{~N} / \mathrm{m}$ \\
\hline
\end{tabular}

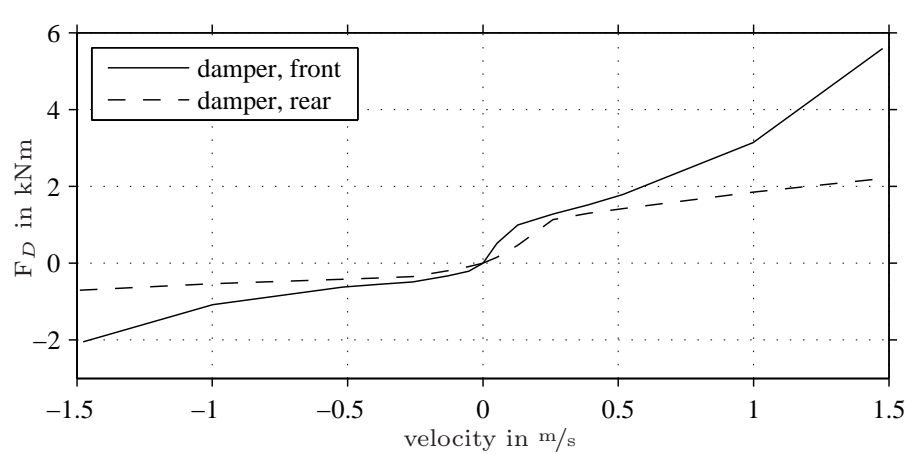

Figure 3. Non-linear damper characteristics from measurements.

\section{3. $\quad$ Fault modelling}

The modelling of the faults was conducted in Matlab/Simulink. Each fault could be applied independently to one or more wheels. Furthermore, the time of the fault occurrence and the duration of the fault were adjustable. Each of the fault groups, as depicted in the Appendix, was physically modelled directly in the component or subsystem where the fault occurs.

The electric faults were based on a detailed model of the electric driveline, as described in Subsection 4.1. Due to the high level of detail, the driveline model ran at a higher sampling rate than the vehicle model. The speed-dependent output torque for the vehicle simulation is important, and was therefore identified in all four quadrants of the electrical machine, thus the full working range was provided. A simplified model for the electric driveline running at the same sampling rate as the vehicle model was derived, resulting in an equation which used several look-up tables for each electric fault. Each of the electric faults falling under FG1 - FG4, was separately identified, curve-fitted and integrated into the vehicle model.

The simplified torque describing the behaviour of FG1, which includes the threephase balanced short circuit, considers a frequency-related correction factor, $\mathrm{K}_{c}$, the mean value $\mathrm{K}_{\bar{T}}$ and the amplitude $\mathrm{K}_{|T|}$ of the faulty torque. The gradient between the healthy and the faulty torque after fault induction is a function of these values as well. Fig. 4 (a) shows the faulty torque characteristics for the operating point $T_{d}=100 \mathrm{Nm}$ and $v_{x}=50 \mathrm{~km} / \mathrm{h}$. This figure shows a congruent overlap of the detailed driveline model results and the results from the simplified model. Note that the simplified model of the torque characteristics has an offset of $+100 \mathrm{Nm}$ for 
(a)

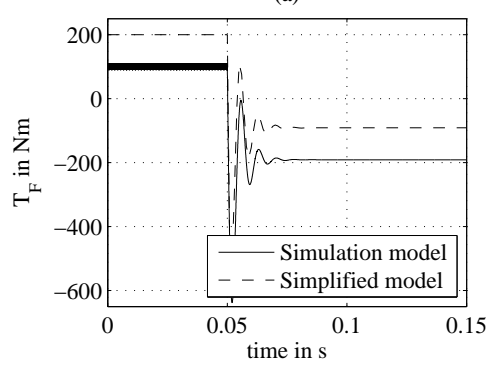

(c)

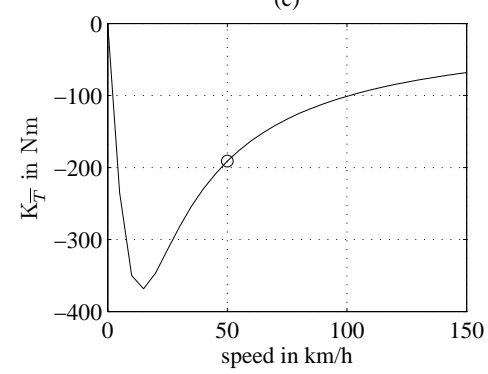

(b)

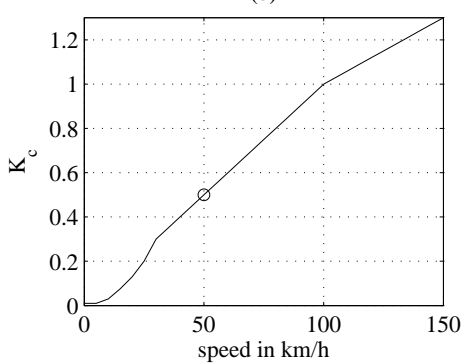

(d)

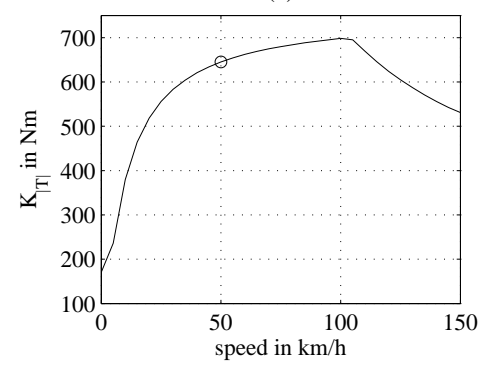

Figure 4. (a) Characteristic torque of a three-phase balanced short circuit with fault induction at $t=0.05 \mathrm{~s}$ plotted together with a simplified model of the faulty torque. Note the offset of the simplified model by $+100 \mathrm{Nm}$ for visualisation purposes. The factors of the simplified faulty torque model include a marker at the working point (o) and are given as: (b) correction factor $\mathrm{K}_{c}$, (c) mean value $\mathrm{K}_{\bar{T}}$, (d) amplitude $\mathrm{K}_{|T|}$.

all electric faults for visualisation purposes. Equation (1) describes the simplified torque for the first fault as follows:

$$
T_{F}(t)=K_{\bar{T}}(\omega)+K_{|T|}(\omega) \sin \left(\gamma_{1} \omega\left(t-t_{F}\right)\right) e^{\frac{\gamma_{2} \omega\left(t_{F}-t\right)}{K_{c}(\omega)}},
$$

with the speed and damping factors $\gamma_{1}=10$ and $\gamma_{2}=1.25$, as well as the rotational speed of the wheel

$$
\omega=\frac{v_{x}}{r_{d y n}}
$$

Equation (1) was fed with the values in the look-up tables shown in Figs. (4 (b)(d) for the first quadrant of the electrical machine. The marker (o) indicates the mentioned working point shown in Fig. 4 (a). The three-phase balanced short circuit resulted in very high braking torques below $50 \mathrm{~km} / \mathrm{h}$, i.e. at urban speeds. The mean value ranged from $-200 \mathrm{Nm}$ to $-350 \mathrm{Nm}$. Above urban speeds, the mean value digressively decreased towards no torque. In contrast to the mean value, the amplitude strongly increased at urban speeds and flattened out afterwards, reaching its peak with $700 \mathrm{Nm}$ at $100 \mathrm{~km} / \mathrm{h}$. This indicates a high impact on the vehicle stability at low speeds.

The inverter shutdown belongs to FG2, and for the simplified model of this fault group, the same factor were employed as for the simplified model of FG1. However, the faulty torque characteristics have a different shape. Fig. 5 (a) shows a strong damping behaviour, which settles quickly towards the mean value identified in the simplified model. The operating point is $T_{d}=100 \mathrm{Nm}$ and $v_{x}=130 \mathrm{~km} / \mathrm{h}$. The first quadrant of the electrical machine is represented by the look-up tables shown in Fig. 5 (b)-(d), which were used in

$$
T_{F}(t)=K_{\bar{T}}(\omega)-K_{|T|}(\omega) \sin \left(K_{c}(\omega) \pi t\right) .
$$




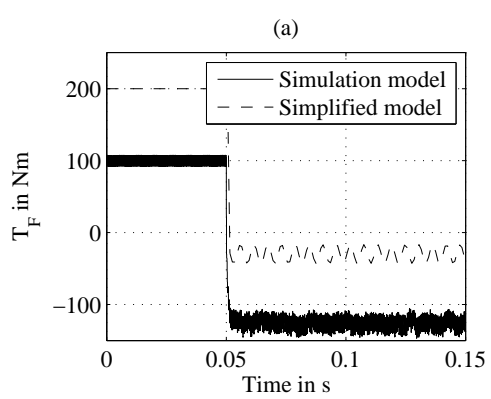

(c)

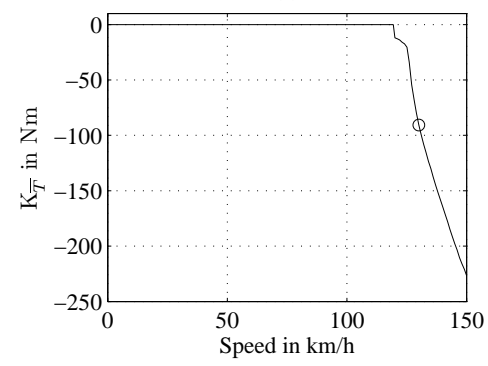

(b)

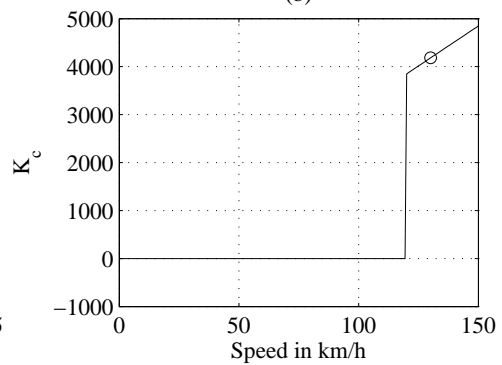

(d)

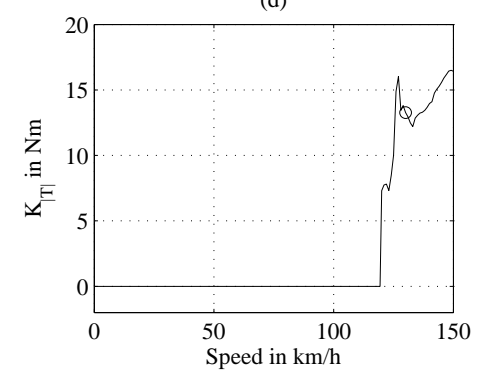

Figure 5. (a) Characteristic torque of an inverter shutdown with fault induction at $t=0.05 \mathrm{~s}$ plotted together with a simplified model of the faulty torque. Note the offset of the simplified model by $+100 \mathrm{Nm}$ for visualisation purposes. The factors of the simplified faulty torque model include a marker at the working point (o) and are given as: (b) correction factor $K_{c}$, (c) mean value $K_{\bar{T}}$, (d) amplitude $K_{|T|}$.

The inverter shutdown shows its potential risk in the field-weakening range especially. While operating at a speed below the nominal speed of the electrical machine, the torque will be reduced to zero. If the working speed is above this nominal speed of the machine, the inverter will produce a magnetic field counteracting the natural magnetic field of the permanent magnets. This helps the machine to turn faster than the nominal speed at the cost of less torque development. If the inverter shuts down during the field-weakening, the suppression of the natural magnetic field disappears and the PMSM develops a speed-dependent braking torque. During reversing, the torque will return to zero, as the speed of the electrical machine is below the field-weakening range.

Fig. 6 (a) shows the faulty torque for a single-transistor turn-on failure, which is one of the faults within FG3. For the operating point of $T_{d}=150 \mathrm{Nm}$ and $v_{x}=100 \mathrm{~km} / \mathrm{h}$ the faulty torque shows high fluctuations around the mean value, which is below the torque of the healthy state. The tables for the simplified model are visualized in Fig. 6 (b)-(d), and can be applied according to

$$
T_{F}(t)=K_{\bar{T}}(\omega)+K_{c}+\frac{1}{2} K_{|T|}(\omega) \sin \left(\gamma_{1} i_{t} \omega^{2}\left(t_{F}-t\right)\right),
$$

with the planetary gear box ratio $i_{p}$ and the speed factor $\gamma_{1}$. The single-transistor turn-on failure also appears in the power electronics. The equivalent circuit diagrams for the modelled faults included in FG2 and FG3 are depicted in Fig. 7 [20].

FG4 includes the current sensor mismatch. The characteristic faulty torque can be seen in Fig. 8. The visualised operating point is at $T_{d}=50 \mathrm{Nm}$ and $v_{x}=50 \mathrm{~km} / \mathrm{h}$. The behaviour shows a clear fluctuation around the mean value, which strongly increases to a level four times higher than the original torque. In contrast to the faults in the previous three fault groups, this fault group also depends on the desired torque $T_{d}$ as shown in

$$
T_{F}(t)=K_{\bar{T}}\left(\omega, T_{d}\right)+\frac{1}{2} K_{|T|}\left(\omega, T_{d}\right) \sin \left(2 \gamma_{1} i_{t} \omega\left(t-t_{F}\right)\right) .
$$


(a)

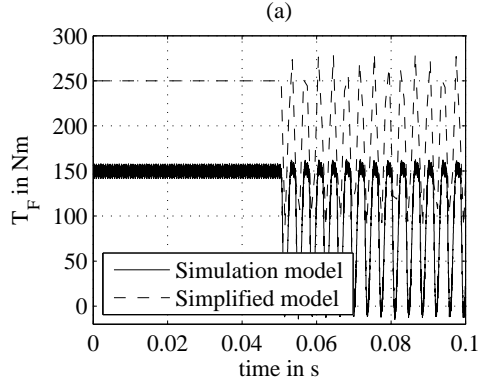

(c)

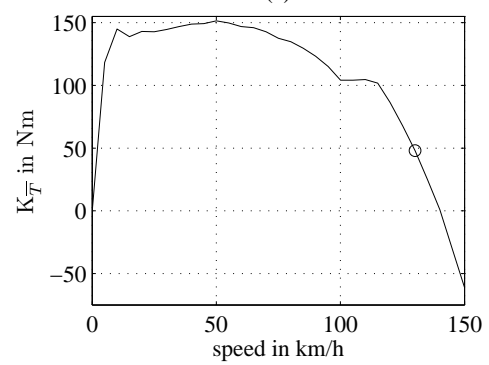

(b)

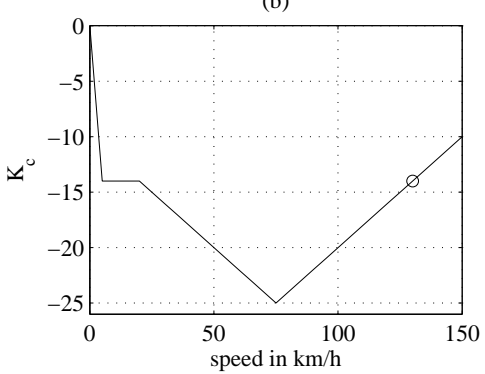

(d)

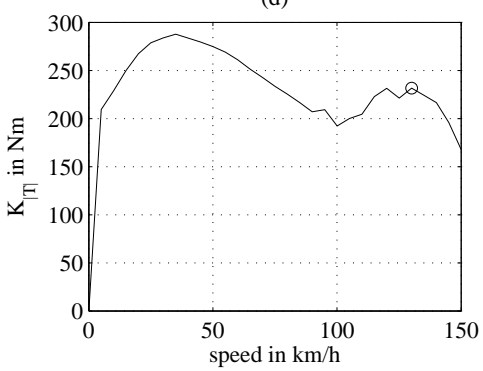

Figure 6. (a) Characteristic torque of a single-transistor turn-on failure with fault induction at $t=0.05 \mathrm{~s}$ plotted together with a simplified model of the faulty torque. Note the offset of the simplified model by $+100 \mathrm{Nm}$ for visualisation purposes. The factors of the simplified faulty torque model include a marker at the working point (o) and are given as: (b) correction factor $\mathrm{K}_{c}$, (c) mean value $\mathrm{K}_{\bar{T}}$, (d) amplitude $\mathrm{K}_{|T|}$.

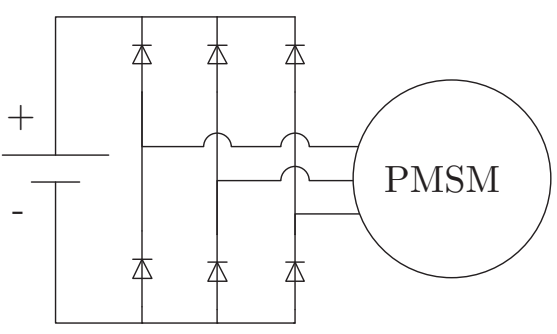

(a)

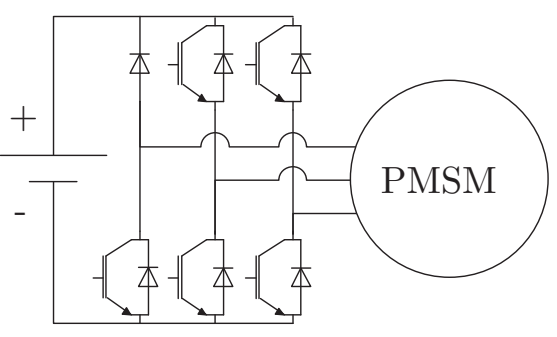

(b)

Figure 7. Types of electric faults. (a) Inverter shutdown. (b) Single transistor turn on failure [20].

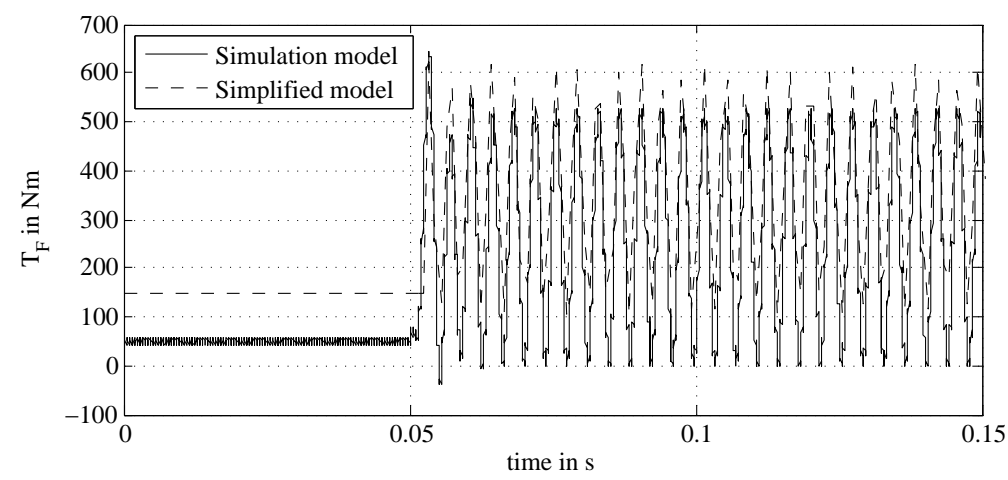

Figure 8. Characteristic torque of a current sensor misalignment failure with fault induction at $t=0.05 \mathrm{~s}$ plotted together with a simplified model of the faulty torque. Note the offset of the simplified model by $+100 \mathrm{Nm}$ for visualisation purposes.

Look-up maps had to be used for the mean value and amplitude, as shown in Figs. 9 and 10 ,

FG5 subsumes all the faults that produce a high positive propulsion torque on the shaft of the electrical machine. FG5 was modelled by maximizing the accelerator 


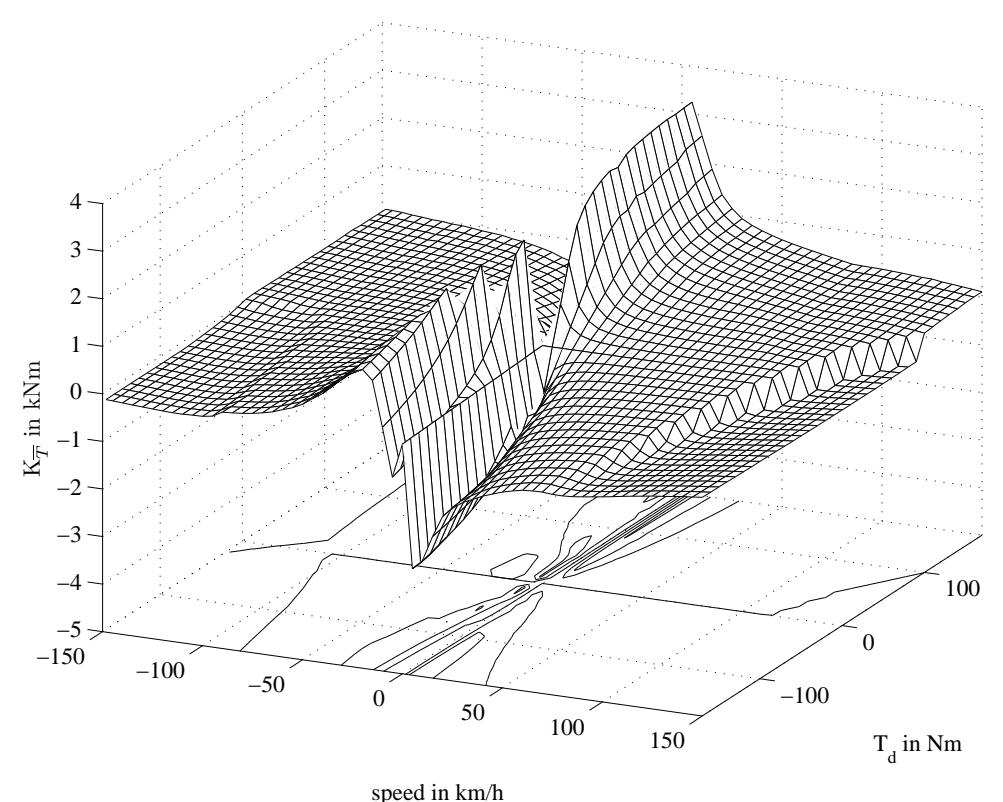

Figure 9. Simplified model of the fault torque mean value $\mathrm{K}_{\bar{T}}$.

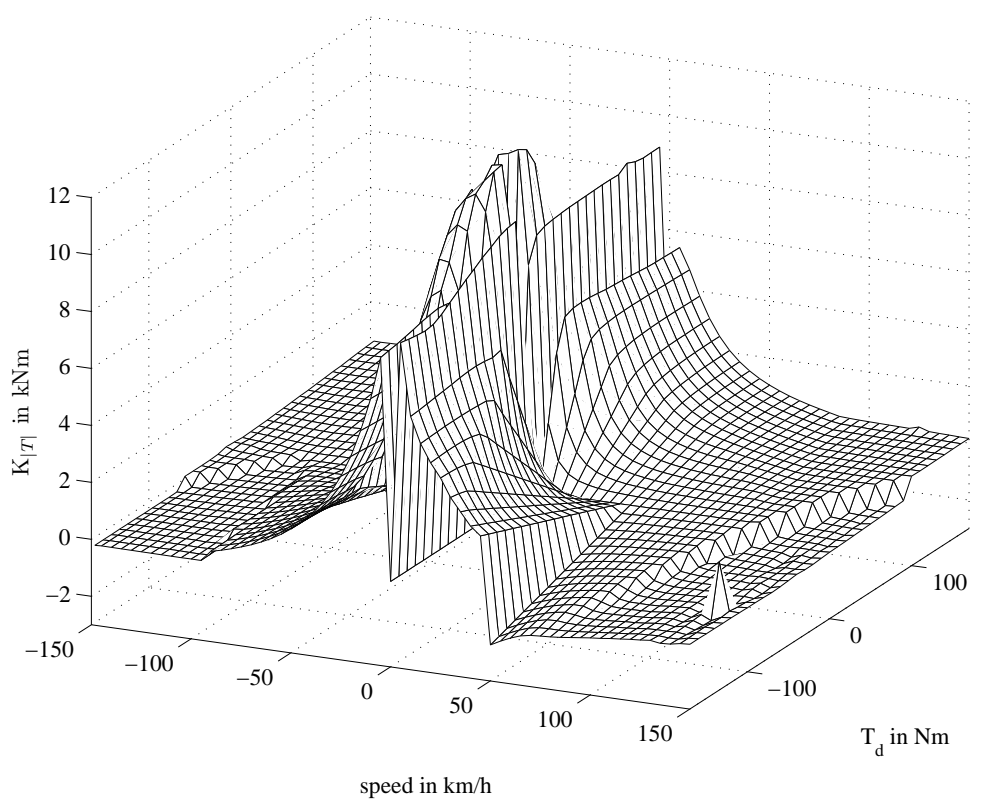

Figure 10. Simplified model of the fault torque amplitude $\mathrm{K}_{|T|}$.

input to the electrical machine and doubling the torque output of the motor.

FG6, FG7, FG9 and FG17 through FG20 were modelled with an adjusted Magic Formula parameter set. Several parameters were adjusted to obtain the desired tyre characteristics. The scale factors used influenced the peak friction coefficient in the $\mathrm{x}$ - and y-direction, $\lambda_{\mu x}$ and $\lambda_{\mu y}$, the brake slip and the cornering stiffness, $\lambda_{K x \kappa}$ and $\lambda_{K y \alpha}$, and the shape of the tyre force as a function of the slip, $\lambda_{C x}$ and $\lambda_{C y}$. All the Magic Formula parameter adjustments are listed in Table 3, The resulting slip-related force curves can be seen in Fig. 11(a) for the longitudinal slip and in Fig. 11(b) for the lateral slip.

Further, FG6 was modelled with a pressure-dependent tyre cornering stiffness. A curve fit had previously been conducted for an experimental study [23] which showed that the tyre cornering stiffness was a function of the tyre pressure. The 
Table 3. Magic Formula parameter adjustments.

\begin{tabular}{ccccccc}
\hline Fault & $\lambda_{\mu x}$ & $\lambda_{\mu y}$ & $\lambda_{K x \kappa}$ & $\lambda_{K y \alpha}$ & $\lambda_{C x}$ & $\lambda_{C y}$ \\
\hline 0 & 1 & 1 & 1 & 1 & 1 & 1 \\
6 & 1 & 1 & $\lambda_{C\left(p_{f, r}\right)}$ & $\lambda_{p_{f, r}}$ & $\lambda_{C\left(p_{f, r}\right)}$ & $\lambda_{p_{f, r}}$ \\
7 & 0.1 & 0.1 & 0.5 & 0.5 & 1 & 1 \\
9 & 0.001 & 0.001 & 0.1 & 0.1 & 1 & 1 \\
17 & 1 & 1 & 0.4 & 0.2 & 1 & 1 \\
18 & 0.75 & 0.75 & 0.9 & 0.9 & 1 & 1 \\
19 & 0.25 & 0.25 & 0.75 & 0.75 & 1 & 1 \\
20 & 0.5 & 0.5 & 0.5 & 0.5 & 1 & 1 \\
\hline
\end{tabular}

(a)

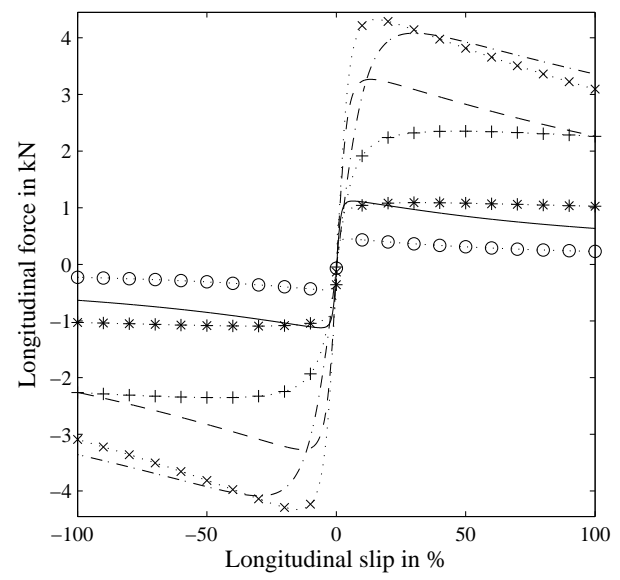

(b)

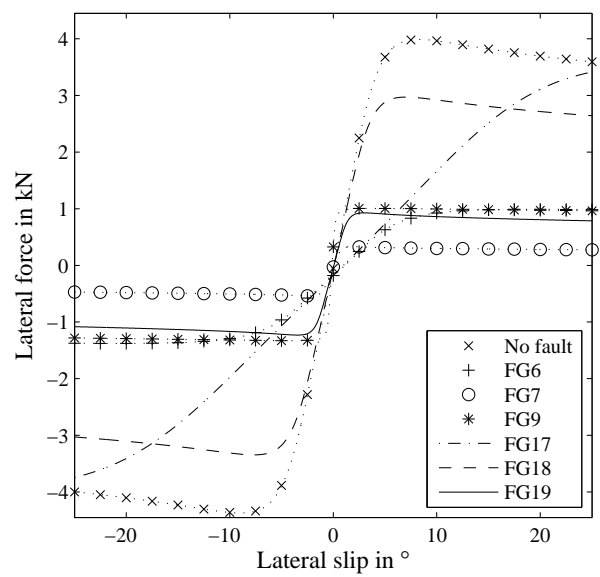

Figure 11. Longitudinal tyre force for different fault conditions.

resulting Equations (6) and (7) are normalized and applicable for a pressure range of 0 bar $<p<2.2$ bar. They served as an input into the tyre model parameters and their coefficients are to be found in Table 4. In this study a tyre pressure of 0.4 bar was chosen for FG6.

$$
\begin{aligned}
\lambda_{C\left(p_{f}\right)} & =\left[\eta_{f, 1} \lambda_{p_{f}}^{3}-\eta_{f, 2} \lambda_{p_{f}}^{2}+\eta_{f, 3} \lambda_{p_{f}}-\eta_{f, 4}\right] \frac{1}{\lambda_{p_{f}}} \\
\lambda_{C\left(p_{r}\right)} & =\left[\eta_{f, 1} \lambda_{p_{r}}^{3}-\eta_{f, 2} \lambda_{p_{r}}^{2}+\eta_{f, 3} \lambda_{p_{r}}-\eta_{f, 4}\right] \frac{1}{\lambda_{p_{r}}}
\end{aligned}
$$

Table 4. Coefficients of the pressuredependent tyre cornering stiffness.

\begin{tabular}{ccccc}
\hline Index $i$ & 1 & 2 & 3 & 4 \\
\hline$\eta_{f, i}$ & 1.7 & $0.2 \mathrm{e}^{3}$ & $7.7 \mathrm{e}^{3}$ & $26 \mathrm{e}^{3}$ \\
$\eta_{r, i}$ & 1.7 & $0.21 \mathrm{e}^{3}$ & $7.7 \mathrm{e}^{3}$ & $14 \mathrm{e}^{3}$ \\
\hline
\end{tabular}

FG8 concerns the blocking of one or more wheels, resulting in the rotational speed being reduced to zero when the fault is induced. In addition to the tyre parameter adjustment that represents a brake disc, the wheel height was lowered to the radius of the brake disc for FG9. This corresponds, for instance, to the loss of a wheel while driving. A small speed-dependent sinusoidal disturbance was introduced in the vertical direction of the wheel for FG10, representing uneven force limitations. 
For FG11 and FG12 a medium and a high brake force, respectively, were applied on the selected wheel(s). No traction torque was transferred between the tyre and the ground for FG13. A sudden return of the steering wheel angle and an increase and decrease in the suspension ride height were implemented in for FG14 - FG16.

In this research study, the driving manoeuvres were limited to steady-state conditions, which do not apply to FG21 - FG31, and therefore their analysis is not presented here.

\section{Selected driving manoeuvres}

Manoeuvres for passenger cars can be divided into dynamic and steady-state manoeuvres, which can be subdivided into straight line driving and cornering. This study was constrained to steady-state driving manoeuvres with straight line driving and cornering conditions up to a lateral acceleration of $4 \mathrm{~m} / \mathrm{s}^{2}$. Higher lateral accelerations are usually not achieved during normal driving, as the resulting side force are perceived by drivers as being quite intensive and the legal regulations, in combination with the road building configurations, are designed to achieve only low to medium lateral accelerations. Fig. 12 visualizes the areas of lateral acceleration for different speeds. The differently marked driving environments include $99.99 \%$ of the driving conditions on regular roads. The probability of occurrence that normal drivers manoeuvre outside this marking on public roads decreases exponentially with increasing lateral acceleration [24]. Based on this, a set of five speeds was selected representing an urban $(50 \mathrm{~km} / \mathrm{h})$, a suburban $(70 \mathrm{~km} / \mathrm{h})$ and a rural speed $(90 \mathrm{~km} / \mathrm{h})$, and two motorway speeds $(110 \mathrm{~km} / \mathrm{h}$ and $130 \mathrm{~km} / \mathrm{h})$. The radius for each cornering manoeuvre was chosen from two levels of lateral acceleration, i.e. $2 \mathrm{~m} / \mathrm{s}^{2}$ and $4 \mathrm{~m} / \mathrm{s}^{2}$. Similar values were found in [25], i.e. values below $a_{y}=3 \mathrm{~m} / \mathrm{s}^{2}$ for the country road speed and below $a_{y}=1 \mathrm{~m} / \mathrm{s}^{2}$ for the motorway speed. Additionally, the five speeds selected were used for the straight line driving manoeuvres. To make the investigation independent of driver reactions, the driver interface was disabled during the fault induction, i.e. the propulsion torque, braking force and steering wheel angle were kept at the same values as they had had just before the fault occurred.

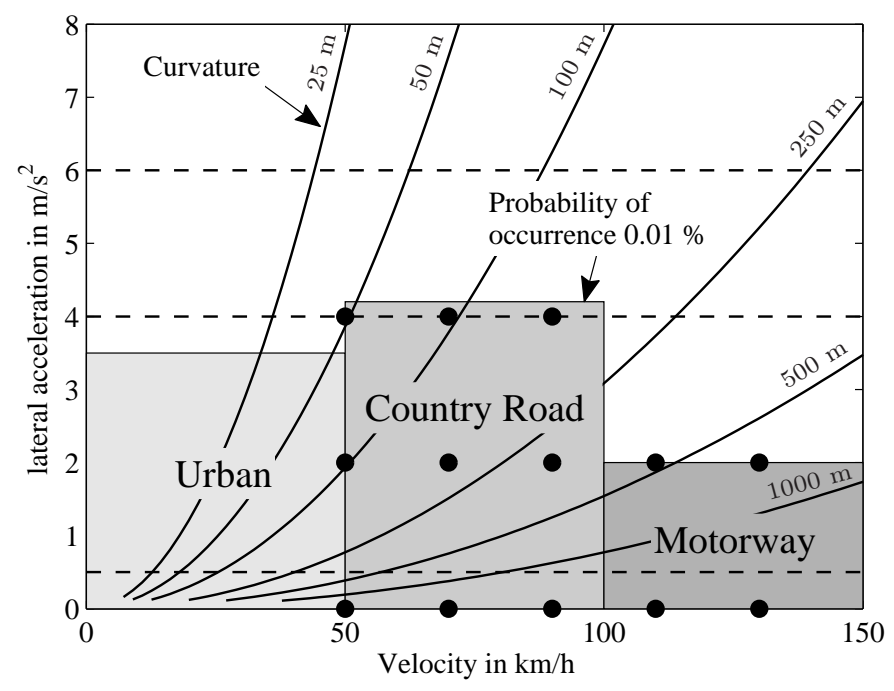

Figure 12. Areas of lateral acceleration for normal driving [24]. 


\section{Controllability ranking}

The evaluation of the simulated faults was conducted according to the functional safety standard for E/E components in the automotive industry, ISO 26262 [26]. Primarily, this standard defines a method of risk estimation for the driver and associated road users on the occurrence of a fault. This risk factor is the result of a combination of three factors, namely exposure, controllability and severity. Exposure defines the frequency and probability of a hazardous situation during operation due to a fault, rated from $E_{0}$ (negligible) to $E_{4}$ (highly probable). Controllability is defined as the probability of preventing specific damage or harm rated from $C_{0}$ (controllable) to $C_{3}$ (uncontrollable). This factor can depend on the driver or on external influences from a motion controller or a failure in a component, for example. Severity specifies the of level of injury to the driver and associated road users that can be caused by a fault, rated from $S_{0}$ (no injury) to $S_{3}$ (life-threatening injury).

The factor of controllability from ISO 26262 was adopted in the proposed fault classification method. The vehicle dynamic reaction to the induced faults was evaluated, and this evaluation was correlated with the specific damage and harm levels of ISO 26262. This standard is also applicable to different chassis and driveline setups as well as other faults due to its generic nature. According to ISO 26262, controllability is divided into the following four classes:

- $C_{0}$ - controllable,

- $C_{1}$ - easy to control,

- $C_{2}$ - difficult to control,

- $C_{3}$ - uncontrollable,

and is composed of three different indices

- $Q_{z}$ - vehicle stability index,

- $Q_{y}$ - lane keeping index,

- $Q_{x}$ - collision avoidance index.

The vehicle stability index $Q_{z}$ is based on an evaluation criterion for load change behaviour introduced by Otto [27], as shown in Equation (8). This criterion contains the yaw rate deviation between the faulty and the healthy vehicle. Furthermore, the yaw acceleration of the faulty vehicle is considered in the index. The advantage of merging the yaw rate deviation and the yaw acceleration is that this approach not only covers a short but strong build-up of the yaw rate that quickly evens out, but also covers a constant yaw acceleration with a changing yaw velocity.

$Q_{z}$ consists of the sum of the mean yaw rate difference $\Delta \dot{\psi}$ between the healthy and the faulty yaw rate of the vehicle, $\dot{\psi}_{h, m}$ and $\dot{\psi}_{f, m}$, and the mean yaw acceleration $\Delta \ddot{\psi}_{f, m}$ in the measured time window of a possible steering correction. In order to make the units consistent, the mean yaw rate difference is divided by the smallest possible reaction time $t_{r}$ after the fault was induced. The vehicle stability index is visualized in Fig. 13 and is written as follows:

$$
Q_{z}\left(t_{r}\right)=\frac{\Delta \dot{\psi}}{t_{r}}+\ddot{\psi}_{f, m}
$$

The reaction time chosen for this study was $t_{r}=0.75 \mathrm{~s}$ after the fault induction, and the corresponding time window is given by $\Delta t_{r}=0.5 \mathrm{~s}$. Both values are based on the analysis conducted in Subsection 6.1, The vehicle stability index was ranked into four classes. Otto [27] provides a value of $Q_{z}=5 \% \mathrm{~s}^{2}$, above which value the 
controllability of the vehicle is not given any more. This value was selected in the present research study representing the highest controllability class $C_{3}$, and three other classes were introduced according to Table 5. Understeering and oversteering were assumed to be equally dangerous in a faulty situation and therefore the absolute value of $Q_{z}$ was taken into account.

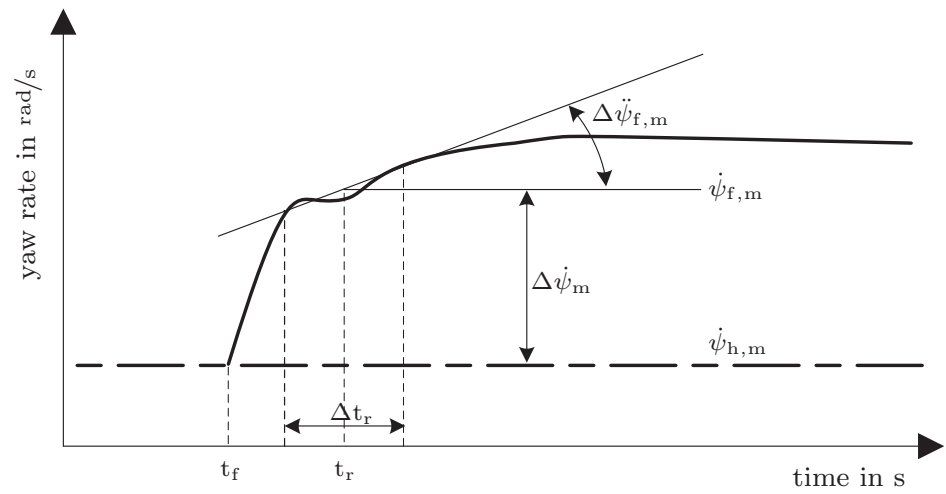

Figure 13. Vehicle dynamic index according to [27].

The lane keeping index $Q_{y}$ concerns the time given in seconds that the first wheel of a faulty vehicle takes to leave a given lane [27]. This index was added because some faults can lead to a deviation from the planned path without the yaw motion being changed to a greater extent; and because situations with only slight changes in the yaw rate, are not covered by vehicle stability index changes. As mentioned in [28], Huriuchi [29] found out that drivers tend more to detect a yaw angle deviation than a lateral position error, supporting the introduction of this index. In the present study, the chosen lane width is $3.5 \mathrm{~m}$. The lane keeping index is visualised in Fig. 14 and defined as follows:

$$
Q_{y}=\min \left(t_{i}\right)
$$

where $t_{i}$ is the time between the fault induction time and the time for the intersection between the edge of the lane on either side and the $i^{\text {th }}$ wheel, which represents the wheel location from the front left to the rear right. The values for the grading of potentially dangerous situations were taken from the average $95^{\text {th }}$ percentile times that were found in Subsection 6.1. Thus, a vehicle is uncontrollable if $Q_{y}<2 \mathrm{~s}$. Other controllability classes for the lane keeping index are to be found in Table 5 .

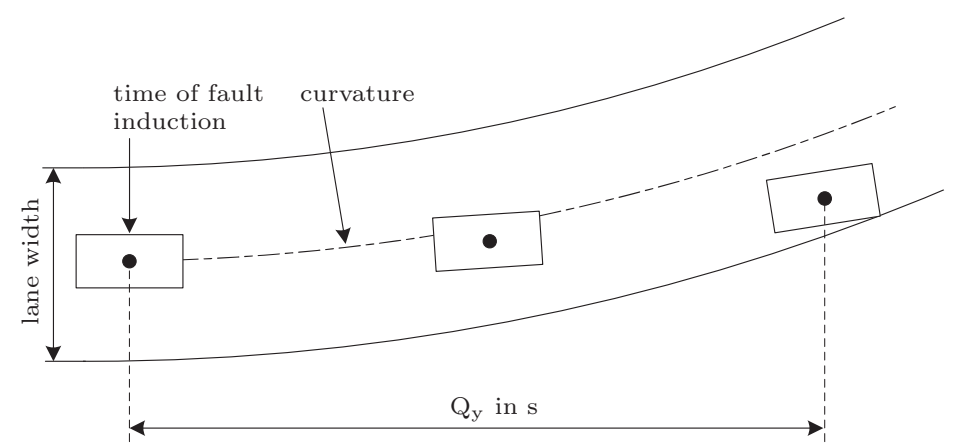

Figure 14. Lane keeping index according to [27]. 
The collision avoidance index $Q_{x}$ was built up in the same way as the vehicle stability index. $Q_{x}$ gives information about the unwanted deceleration or acceleration that can lead to a rear-end collision. The previously mentioned reaction time and time window were also applied when creating this index. $Q_{x}$ uses the mean longitudinal speed difference $\Delta v_{x}$ between the healthy and the faulty longitudinal speed of the vehicle, $\bar{v}_{x, h}$ and $\bar{v}_{x, f}$, and the mean longitudinal acceleration $\bar{a}_{x, f}$, leading to

$$
Q_{x}\left(t_{r}\right)=\frac{\Delta v_{x}}{t_{r}}+\bar{a}_{x, f}
$$

The collision avoidance index covers not only fast and short accelerations with quick speed deviations that even out, but also slow but constant accelerations with a constant change in speed. For the analysis, absolute values were considered. The grading of the controllability classes for this index is shown in Table 5, and was derived from the studies about regenerative braking listed in Subsection 6.2.

The fault influence index $Q_{f}$ was determined by adding up the controllability class values of the vehicle stability index $Q_{z}^{*}$, the lane keeping index $Q_{y}^{*}$ and the collision avoidance index $Q_{x}^{*}$ as follows:

$$
Q_{f}=Q_{z}^{*}+Q_{y}^{*}+Q_{x}^{*}
$$

The controllability class values $Q_{z, y, x}^{*}$ are non-linear and are listed in Table 6. The non-linearity ensures that the fault influence index $Q_{f}$ is also rated with $C_{3}$, if any of the three indices has a $C_{3}$ rating or if all three have a $C_{2}$ rating. All other combinations result in a $C_{2}$ rating or lower.

\subsection{Reaction time}

The reaction time is a research topic in its own right and, for the mentioned evaluation indices, an important input parameter. A brief description follows of how the reaction time for this study was chosen. The reviewed literature is shown in Table 7.

The reaction time is the time between the occurrence of a disturbance and the driver's reaction to this situational change by reaching the desired subsystem (e.g. brake-pedal, accelerator or steering wheel movement). The reaction time can be decomposed into the mental processing time and the movement time, which run in sequential order. The mental processing time is divided into four phases - sensation, recognition, situational awareness, and response selection and programming. The sensation phase concerns the time that the human auditory and visual sensors need to detect an object on the road. The time spent interpreting what the object in question is, e.g. a person, a car or an obstacle, is called the recognition phase. The situational awareness phase concerns the time needed to put the recognized object into context and to interpret the scene, as well as forecast what will happen

Table 5. Controllability class definition of the three indices.

\begin{tabular}{ccccc}
\hline Controllability classes & $C_{0}$ & $C_{1}$ & $C_{2}$ & $C_{3}$ \\
\hline$\left|Q_{z}\right|$ in $/ \mathrm{s}^{2}$ & $<2$ & $2-3.5$ & $3.5-5$ & $>5$ \\
$\left|Q_{y}\right|$ in s & $>5$ & $5-3$ & $3-2$ & $<2$ \\
$\left|Q_{x}\right|$ in $\mathrm{m} / \mathrm{s}^{2}$ & $<0.8$ & $0.8-2.25$ & $2.25-3$ & $>3$ \\
\hline
\end{tabular}


Table 6. Ranking of the controllability classes of the three indices and the final fault influence index.

\begin{tabular}{ccccc}
\hline Controllability classes & $C_{0}$ & $C_{1}$ & $C_{2}$ & $C_{3}$ \\
\hline$Q_{x, y, z}^{*}$ & 1 & 2 & 3 & 9 \\
$Q_{f}$ & 3 & 4 & $5-8$ & $>=9$ \\
\hline
\end{tabular}

in the scene. In the fourth phase, one considers whether a response is needed and, if so, one selects the response needed and programs mentally the appropriate movement. The duration of the second and third steps in the fourth phase are summed together under the time for response selection and programming. Often the mental processing time is referred to as the perception time. The movement time covers the time that is needed to carry out the muscle movement required for the programmed response. Moving one's foot from the accelerator to the brakepedal is an example. When discussing reaction times, a third element of time should be considered, namely the device response time. The device response time covers the delay times for mechanical, hydraulic and even electrical devices, and therefore comes between the driver's action and the force generation of the device. This third element of time was neglected in this study, since different modes of device actuation have different delays. The main focus is on the driver reaction time, which includes only the mental processing and the movement time 30].

The driver reaction time is influenced by several factors, such as the cognitive load and the visibility as well as the driver's age and expectation. In the analysis performed in this study, faults occurred suddenly without any warning being given to the driver, and therefore the expectation factor was crucial; especially important was the driver's reaction time when faced with unexpected or surprising events. Green [30] divides the alertness into three classes:

- "Expected" - the driver is alert and aware of the upcoming necessary action (e.g. braking). This gives the best reaction time with $0.7 \mathrm{~s}$.

- "Unexpected" - the driver is neither alert nor aware of the upcoming necessary action and detects a common road signal (e.g. the braking of a car ahead). The reaction time here is $1.25 \mathrm{~s}$.

- "Surprise" - the driver is neither alert nor aware of the upcoming necessary action and experiences an unusual situation (e.g. a child is walking out from behind a parked car). The reaction time here is $1.5 \mathrm{~s}$.

A representative experiment for determining the driver reaction time in unexpected situations was conducted by Johansson and Rumar [31]. The test subjects $(\mathrm{N}=321)$ had to brake as soon as they heard a sound, in both expected and unexpected situations. The estimated mean value for the reaction time for the expected and the unexpected events was $0.7 \mathrm{~s}$ and $1.0 \mathrm{~s}$, respectively. Otto [27] analysed the load change behaviour of different vehicles with simulator and real driving experiments. The drivers were prepared for a vehicle reaction and therefore the average reaction time for expected events was for the simulator between $0.5 \mathrm{~s}$ and $1.0 \mathrm{~s}$ and for the real driving experiment $0.75 \mathrm{~s}$. It was found that with higher lateral accelerations, which correlate with higher yaw rates, the reaction time becomes shorter for the test objects. In a study performed by Schmitt et al. [32], an experiment with the sudden braking of a vehicle ahead was conducted. The average reaction time was $0.72 \mathrm{~s}\left(1.0 \mathrm{~s}\right.$ for the $95^{\text {th }}$ percentile reaction time) for normal braking and $0.9 \mathrm{~s}(1.42 \mathrm{~s})$ for emergency braking.

Recently, Ma et al. 33 presented a study with experimental results from real driving and simulator experiments. Anticipated danger resulted in a mean reaction 
time of $0.42 \mathrm{~s}$ for the real driving experiment. On the other hand, sudden danger without anticipation resulted in mean values of $1.1 \mathrm{~s}$ and $0.9 \mathrm{~s}$, for the real driving and the simulator experiment, respectively. The driver reaction time in real traffic was analysed by Ma et al. and Fambro et al. [33, 34]. The results showed that an unexpected object scenario under controlled and open road conditions gave a mean perception-brake response time of about $1.1 \mathrm{~s}$ and a $95^{\text {th }}$ percentile perception-brake response time of $2.0 \mathrm{~s}$, thus including most drivers. The latter time is below the American Association of State Highway and Transportation Officials' perception-brake response time of $2.5 \mathrm{~s}$, which is used as an appropriate value for highway design. A study on crash avoidance was conducted in [35] comparing test track and simulator results for a sudden intersection crash scenario. The mean reaction time for releasing the throttle was $0.96 \mathrm{~s}$ in the simulator experiments and $1.28 \mathrm{~s}$ in the test track experiments. The test subjects had a mean reaction time to initial steering for the simulator and test track experiments of $1.64 \mathrm{~s}$ and $1.67 \mathrm{~s}$, respectively. This study also distinguished between braking and steering decisions. Summala [36] conducted a steering response experiment with the sudden opening of a door of a car parked at the edge of the road. The average steering reaction time was $1.5 \mathrm{~s}$. Summala's [36] results show smaller reaction times for steering decisions when considering the response time of the vehicle. Hankey claimed that the steering response was $0.3 \mathrm{~s}$ faster than the braking response as cited in [30]. Another study with a tyre blow-out test resulted in a steering reaction time of only $0.5 \mathrm{~s}$ [37]. This low value might have been caused by the sound of the tyre explosion kit that was used, the full alertness of the test person and the fact that humans react faster to audible signals. Secondly, the test was not statistically sound.

Since the results were not always measured in the same way in the studies referred to above, and since the movement time was not always included in the reaction times of these studies, an estimate of the movement time was made based on the selected literature and added to the reaction times. One single value for the reaction time does not exist, but a trend can be seen in the studies presented. The reaction time selected for the analysis performed in the present study was therefore based on an average of $0.75 \mathrm{~s}$. This coincides with the value used for Otto's criterion, and therefore no adaptation was made and the original values could be used as stated in [27].

Table 7. Selected publications on driver reaction time experiments

\begin{tabular}{lcccc}
\hline Reference & $\begin{array}{c}\text { Reaction time } \\
\text { - expected } \\
\text { events }\end{array}$ & $\begin{array}{c}\text { Reaction time } \\
- \text { unexpected } \\
\text { events }\end{array}$ & Actuation & Environment \\
\hline Green 2000 & $0.7 \mathrm{~s}$ & $1.25-1.5 \mathrm{~s}$ & braking & - \\
Johansson et al. 1971 & $0.7 \mathrm{~s}$ & $1.0 \mathrm{~s}$ & braking & simulator \\
Ma et al. 2005 & $0.42 \mathrm{~s}$ & $1.1 \mathrm{~s}$ & braking & test track \\
Ma et al. 2005 & - & $0.9 \mathrm{~s}$ & braking & simulator \\
Fambro et al. 1998 & $0.7 \mathrm{~s}$ & $1.1 \mathrm{~s}$ & braking & real traffic \\
McGehee et al. 2000 & - & $0.96 \mathrm{~s}$ & braking & simulator \\
McGehee et al. 2000 & - & $1.28 \mathrm{~s}$ & braking & test track \\
Schmitt et al. 2007 & $0.72-0.9 \mathrm{~s}$ & - & braking & test track \\
Otto 1987 & $0.75 \mathrm{~s}$ & - & steering & simulator \\
Otto 1987 & $0.5-1.0 \mathrm{~s}$ & - & steering & test track \\
McGehee et al. 2000 & - & $1.64 \mathrm{~s}$ & steering & simulator \\
McGehee et al. 2000 & - & $1.67 \mathrm{~s}$ & steering & test track \\
Summala 1981 & - & $1.5 \mathrm{~s}$ & steering & real traffic \\
Blythe et al. 1998 & - & $0.5 \mathrm{~s}$ & steering & test track \\
\hline
\end{tabular}




\subsection{Active deceleration}

The grading for the collision avoidance index $Q_{x}$ was based on the deceleration of vehicles. Several publications have appeared on the subject of regenerative braking and braking during the application of adaptive cruise control. Subsumed under active deceleration, the maximum values used for regenerative braking and adaptive cruise control are listed in Table 8 , Adaptive cruise control is, nevertheless, a comfort-related system, and therefore the deceleration is limited to values between $-2 \mathrm{~m} / \mathrm{s}^{2}$ and $-3 \mathrm{~m} / \mathrm{s}^{2}$ nowadays [24]. Several experiments have been conducted by different research groups on regenerative braking intensity. Schmitz et al. [38] tested

Table 8. Selected publications on deceleration values

\begin{tabular}{lcc}
\hline Source & Deceleration values & Comment \\
\hline Bosch 2007 & $-2 \mathrm{~m} / \mathrm{s}^{2}$ to $-3 \mathrm{~m} / \mathrm{s}^{2}$ & $\begin{array}{c}\text { comfort level } \\
\text { Schmitz et al. } 2012\end{array}$ \\
Eberl et al. 2012 & $-0.8 \mathrm{~m} / \mathrm{s}^{2}$ to $-2.25 \mathrm{~m} / \mathrm{s}^{2}$ & $\begin{array}{l}\text { regenerative braking } \\
\text { regenerative braking }\end{array}$ \\
\hline
\end{tabular}

deceleration values up to a maximum of $-1.6 \mathrm{~m} / \mathrm{s}^{2}$ in a driving simulator experiment. The values tested included values higher than the value produced by the average drag torque during normal driving operation, i.e. $-0.8 \mathrm{~m} / \mathrm{s}^{2}$, and values higher than the typical deceleration value during driving in urban areas, i.e. $-1.0 \mathrm{~m} / \mathrm{s}^{2}$, as stated in [39]. Eberl et al. [39] conducted real traffic experiments with three different deceleration values, $-0.8 \mathrm{~m} / \mathrm{s}^{2},-1.5 \mathrm{~m} / \mathrm{s}^{2}$ and $-2.25 \mathrm{~m} / \mathrm{s}^{2}$, two of which are higher than the previously mentioned typical deceleration value for the drag torque; of these values the strongest was perceived as the most positive by the drivers. The controllability classes for the collision avoidance index $Q_{x}$ were derived from these studies as seen in Table 5 .

\section{Results}

The results presented here concern eight out of the 31 different fault groups. The selection includes all the fault groups based on electric faults (FG1 - FG5), as well as three fault groups based on important mechanical and hydraulic faults (FG6 FG8). FG6 - FG8 subsume faults that can occur in regular vehicles as well, e.g. punctures, low friction levels and locked wheels; of which the last mentioned is the fault with the highest severity in this analysis. The controllability classes presented in Table 5 are visualized in Table 10 and the figures below with the help of the colour-map given in Table 9.

A deviation from the vehicle's intended path can occur during fault induction. The vehicle can increase its understeering or oversteering behaviour, leading to a lateral offset and a yaw rotation. Moreover, the fault can decelerate or accelerate the vehicle, so that traffic participants in front of or behind the vehicle are exposed to hazards. These vehicle reactions are represented by the three indices $Q_{z}, Q_{y}$ and $Q_{x}$, and are illustrated with three examples. The different behaviours are displayed in Figs. [15 and [16. For the curving manoeuvre, the selected driving speed was $90 \mathrm{~km} / \mathrm{h}$ and the given lateral acceleration was $2 \mathrm{~m} / \mathrm{s}^{2}$, for FG1, FG7 and FG8.

For FG1, the fault induction occurred at the outer rear wheel after $0.5 \mathrm{~s}$. The vehicle started to understeer, which led to a lateral deviation from the planned trajectory. After $55 \mathrm{~m}$, or just above $2.2 \mathrm{~s}$, the lateral offset was larger than $1 \mathrm{~m}$, and the vehicle left the given road, assuming a standard road width of $3.5 \mathrm{~m}$. 
Table 9. Colour-map for the controllability classes of the three indices

\begin{tabular}{lccccc}
\hline Controllability classes & $C_{0}$ & \multicolumn{1}{c}{$C_{1}$} & $C_{2}$ & $C_{3}$ \\
\hline Legend colour & white & light gray & gray & dark gray \\
\hline
\end{tabular}

The motion paths in Fig. 16 visualize a constant longitudinal deceleration and a gradual decrease in the normalized lateral acceleration in the first second after fault induction. These values are low, so that the vehicle speed is not significantly influenced, as can be seen in Fig. 16(c). The yaw rate decreases in the same manner as the normalized lateral acceleration. It can be seen from the results in Table 10 that the main influence on the controllability was exerted by the lane keeping index, while the influence of the vehicle stability index and the collision avoidance index were almost negligible.

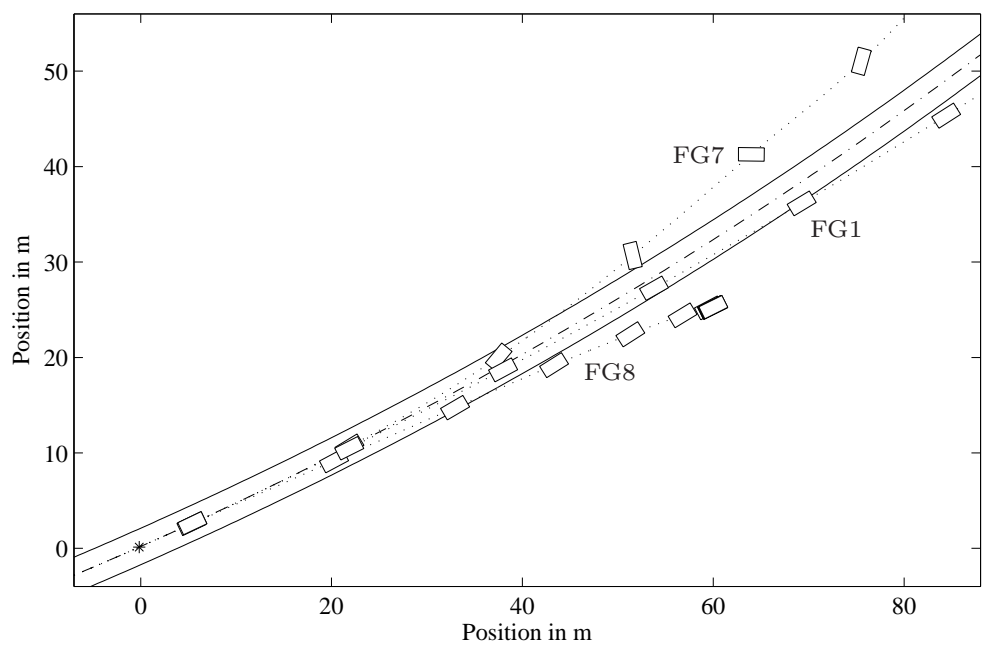

Figure 15. Trajectories for three different fault groups (dotted line), as well as the healthy path (dashdotted line) and the lane border marking (solid line). Fault induction at marker $(\star)$.
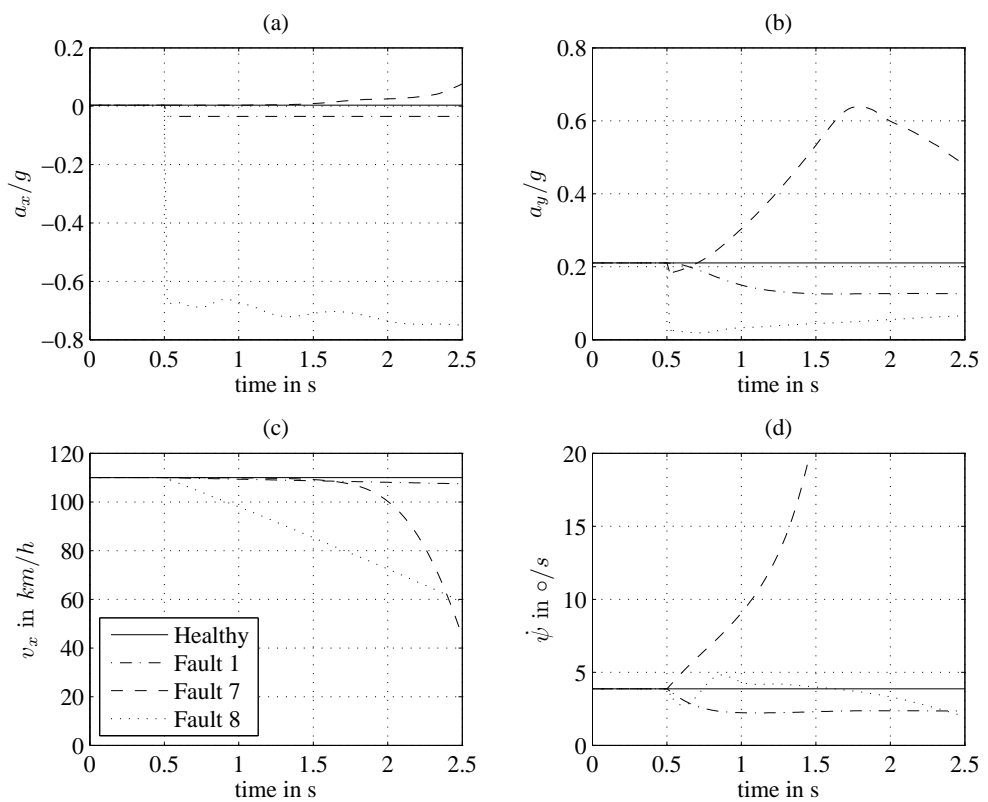

Figure 16. Motions for three different faults - lateral and longitudinal acceleration, longitudinal velocity and yaw rate. 
Table 10. Controllability classes of the three indices for FG1, FG7 and FG8

\begin{tabular}{ccccc}
\hline Fault group & $Q_{z}$ & $Q_{y}$ & $Q_{x}$ & $Q_{f}$ \\
\hline FG1 & 2 & 3 & 1 & 6 \\
FG7 & 9 & 3 & 1 & 13 \\
FG8 & 2 & 9 & 9 & 20 \\
\hline
\end{tabular}

The same fault location and induction time were chosen for the example from FG7. The friction level reduction for wheel 4 led to a reduction in the maximum tyre forces, and therefore the tyre side force on the rear axle desired to keep the vehicle on course could not be transferred to the ground. This led to a loss of stability, resulting in a sudden yaw rate increase. Due to the uncontrolled rotation of the vehicle, it also left the track quickly, see Fig. 16. The indices $Q_{z}$ and $Q_{y}$ exerted an influence on the controllability, while, due to the lack of speed reduction, $Q_{x}$ did not behave that way, as displayed in Table 10.

In the case of FG8, the fault was applied to all four wheels after $0.5 \mathrm{~s}$, leading to a strong deceleration of around $-7 \mathrm{~m} / \mathrm{s}^{2}$. The friction utilisation in the longitudinal direction was maximized, and therefore the lateral forces could not be kept at the same levels as before the fault induction. Both these phenomona can be seen in Fig. 16. This led to a $C_{3}$ classification in the collision avoidance index $Q_{x}$ and the lane keeping index $Q_{y}$, as seen in Table 10. The changes in $Q_{z}$ had less influence.

The results for FG1, which comprises the three-phase balanced short circuit, are presented in Fig. 17. In general this fault did not reach controllability class $C_{3}$ for the fault influence index $Q_{f}$, but it was constantly in the $C_{2}$ class for all the analysed combinations. The vehicle stability index $Q_{z}$ shows that the impact of FG1 was higher at lower speeds, independent of the lateral acceleration. This corresponds to the mean value of the faulty torque, which was high at low speeds. Fig. 17 also shows that FG1 had a small impact on $Q_{z}$ compared to its effect on the lane keeping index $Q_{y}$. The lane keeping index shows more combinations in the $C_{2}$ class. Furthermore, the influence of FG1 on the inner wheels during cornering was higher, leading to the conclusion that the friction utilisation level in the longitudinal direction was high, and only a small lateral force was built up on the faulty wheel.

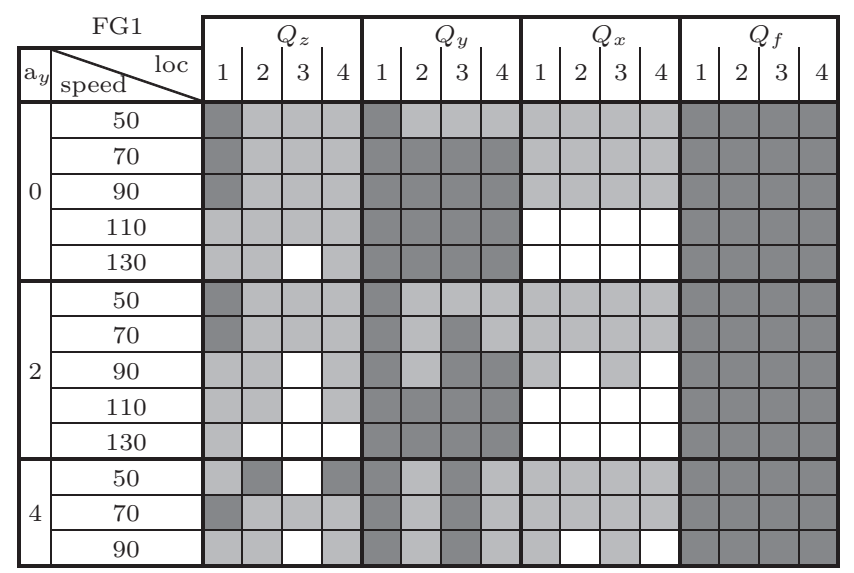

Figure 17. Controllability ranking results for FG1.

The results for FG2, which comprises the inverter shutdown, are shown in Fig. 18 . The field-weakening range is clearly visible from $90 \mathrm{~km} / \mathrm{h}$ and faster. The vehicle 


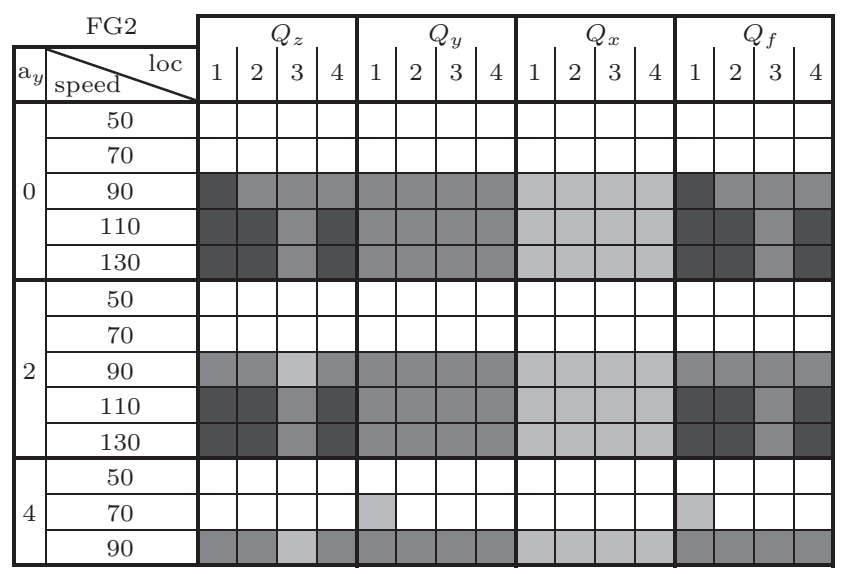

Figure 18. Controllability ranking results for FG2.

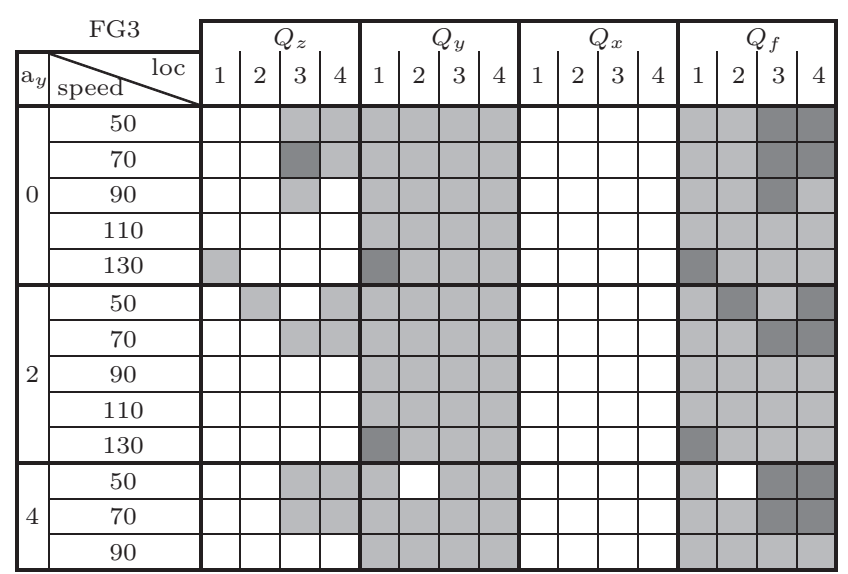

Figure 19. Controllability ranking results for FG3.

became uncontrollable, and therefore ended up in controllability class $C_{3}$ for speeds higher than $110 \mathrm{~km} / \mathrm{h}$ for the all wheels but the third. The vehicle stability index had the highest influence on the fault classification index $Q_{f}$. On the other hand, the collision avoidance index had only a small influence as the brake torque was not large enough to generate a high retardation of the vehicle.

FG3 is a group of weak faults, and therefore most combinations of the fault influence index $Q_{f}$ had controllability class $C_{1}$. The fault controllability was mainly influenced by the lane keeping index $Q_{y}$, see Fig. 19. Both the other indices, $Q_{z}$ and $Q_{x}$, show that, for most of the combinations, FG3 was fully controllable. In the lower speed region, some combinations reach class $C_{2}$.

FG4, which includes the current sensor mismatch, showed stronger uncontrollability at high speeds. At the top motorway speed of $130 \mathrm{~km} / \mathrm{h}$ FG4 was rated in controllability class $C_{3}$ for all four locations, as seen in Fig. 20. Below that speed, the lane keeping index can be seen as the critical one, as $Q_{z}$ did not exert an influence on the fault controllability and $Q_{x}$ had a moderate $C_{1}$ rating. Thus, this fault group led mostly to a critical situation without the driver feeling the response of the vehicle, but merely experiencing a smooth deviation from the desired lane.

A sudden increase in the traction torque, which falls under FG5, led to vehicle stability issues, see Fig. 21. $Q_{z}$ was for most of the combinations in class $C_{3}$, while the other two indices, $Q_{y}$ and $Q_{x}$, were mainly in class $C_{2}$. At higher speeds, this fault was less severe, as the torque increase was not as high any more due to the friction losses. 


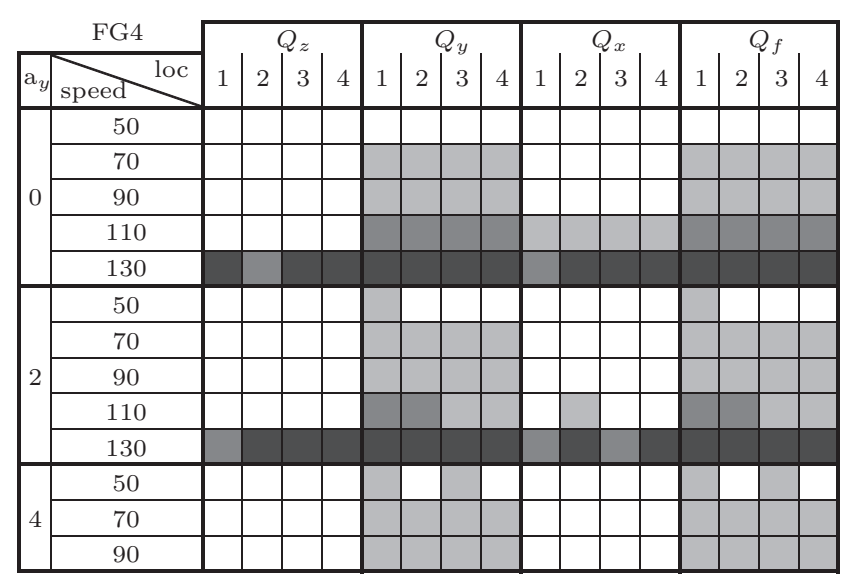

Figure 20. Controllability ranking results for FG4.

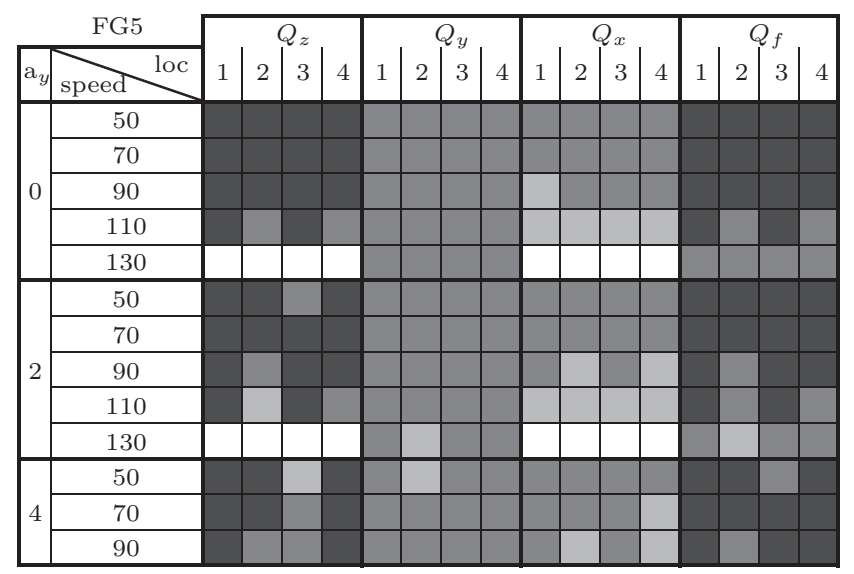

Figure 21. Controllability ranking results for FG5.

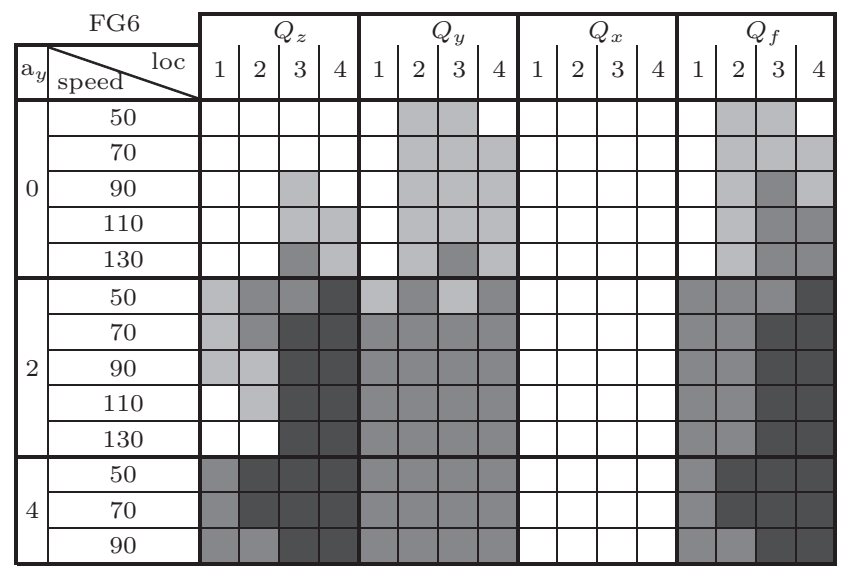

Figure 22. Controllability ranking results for FG6.

A puncture is one of the faults subsumed within FG6. It was mainly critical situations that occurred with this kind of fault, if the fault happened on the rear axle during a cornering manoeuvre. The vehicle stability was lost in most cases, as seen by the results for $Q_{z}$ in Fig. 22. The collision avoidance index can be ignored, because there was either little or no speed decrease.

FG7 was not only applied to each wheel separately, but also to the left and right side (wheels $1+3$ and wheels $2+4$ ) and to all the wheels together. This fault group incorporates $\mu$-split conditions and low ground friction. Cornering manoeuvres in 


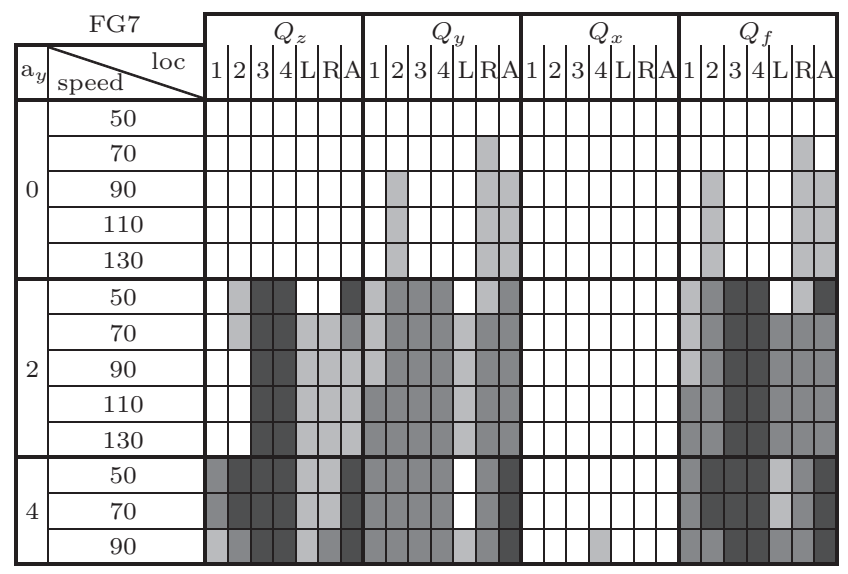

Figure 23. Controllability ranking results for FG7.

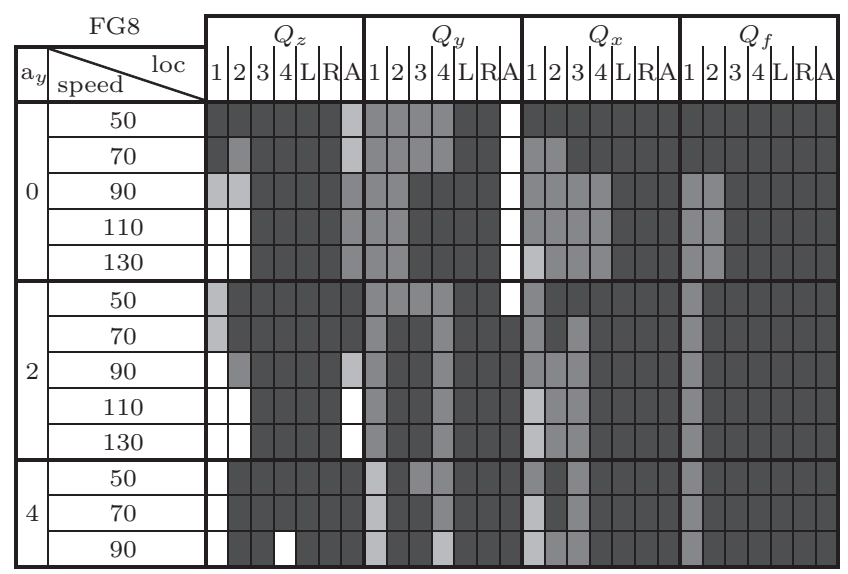

Figure 24. Controllability ranking results for FG8.

particular were dangerous with this kind of fault acting on the rear axle, because of the low maximum force transfer to the ground. At higher lateral acceleration, low friction on all the wheels was also rated in controllability class $C_{3}$, mainly in $Q_{z}$. Since the speed did not change, so that the collision avoidance index was negligible. The lane keeping index was mostly in the region of class $C_{2}$, and its influence was therefore less severe than the $Q_{z}$ influence. The results of FG7 are illustrated in Fig. 23.

The last fault group of the selection to be presented is FG8. It is the fault group with the most severe fault in this analysis, i.e. the locked wheel. The results shown in Fig. 24 indicate a high incidence of class $C_{3}$ for the fault influence index $Q_{f}$, as well as for the separate indices. For the fault location of wheel 1, the fault had controllability class $C_{2}$ during cornering manoeuvres. The same controllability class was found during straight line driving for the fault locations of wheel 1 and wheel 2 , and speeds above $70 \mathrm{~km} / \mathrm{h}$.

Fig. 25 shows the summarized results of the study. The highest controllability class of the fault influence index $Q_{f}$ for all the fault locations was selected for each manoeuvre and plotted against the vehicle speed for the three tested lateral accelerations. Most of the fault groups reached controllability class $C_{3}$ at one or more speeds and lateral accelerations. The exceptions were FG1 and FG3, which did not reach the highest class, but whose maximum ranking was class $C_{2}$. FG1 was constantly ranked in controllability class $C_{2}$, while FG3 fluctuated between class $C_{1}$ and $C_{2}$, constantly being placed lower than FG1. These two fault groups 
are considered to be the ones comprising the weaker faults in this analysis. The inverter shutdown in FG2 showed a clear indication of the field weakening range, with a $C_{3}$ ranking for motorway speeds and almost no influence at lower speeds, where it had a $C_{0}$ ranking. FG4, which includes the current sensor mismatch, was placed in a low controllability class, except at a speed of $130 \mathrm{~km} / \mathrm{h}$. At this speed and for all the fault locations FG4 had controllability class $C_{3}$, indicating loss of control. The controllability class of the gain fault of FG5 decreased with a speed increase. This is contrary to the results for all the other faults, and can be explained by the decrease in torque with increasing speed due to the field-weakening range. The results for the three mechanical and hydraulic fault groups are displayed as
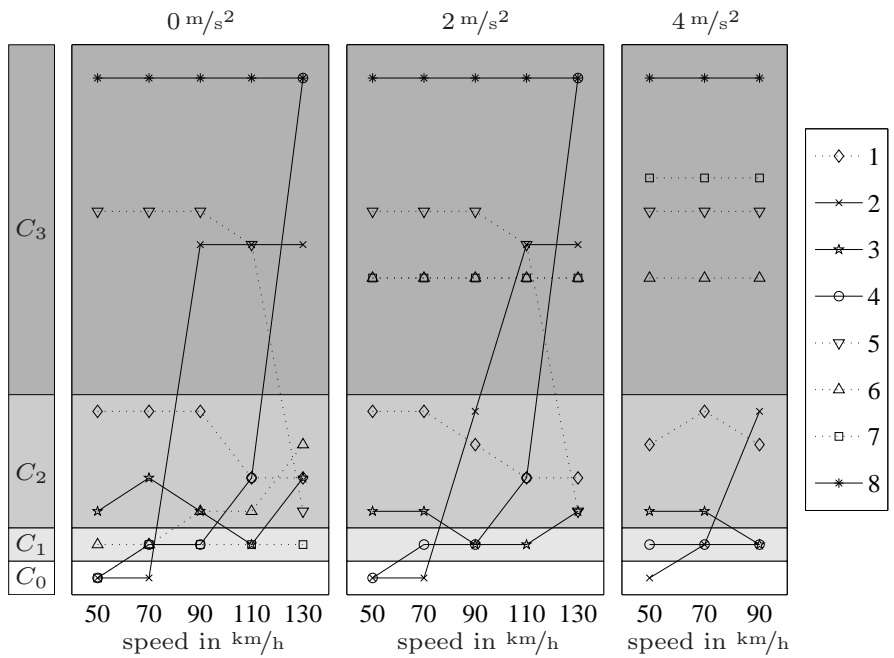

Figure 25. Controllability ratings of the selected faults for the three studied lateral accelerations.

well. The ratings for the puncture, which falls under FG6, point out the positive correlation between the lateral acceleration and the controllability class in a similar way to the ratings for FG7. Low friction, which is subsumed under FG7, was rated in the highest controllability class, $C_{3}$, during the cornering manoeuvres, while the vehicle did not react to a great extent during straight line driving. The locked wheel failure in FG8 showed clearly its high danger by reaching the peak value for each manoeuvre. It has to be noted that the manoeuvres were performed in steady-state conditions. The actual vehicle reaction will be strongly related to the influence of the driver changing the vehicle state. This study focuses on illustrating which faults have the largest influence on the vehicle behaviour.

\section{Conclusions}

The research study presented herein has analysed the effects of electrical, mechanical and hydraulic faults in electric vehicles. Fault simulation models have been developed for each fault group, and a methodology for classifying the faults according to their level of controllability has been proposed. The fault classification has focused on the main vehicle dynamic effects of these faults, i.e. their effects on the vehicle stability, lane keeping and rear-end collision hazards. Each of these three aspects is represented by an index that has been classified according to the functional safety standard for $\mathrm{E} / \mathrm{E}$ components in the automotive industry, ISO 26262. The vehicle stability index covers the deviation of the yaw motion, the lane keeping index indicates the length of time before a predefined lateral offset has been reached, and the collision avoidance index indicates the deviation in the longitudinal direction. The three indices have been ranked in one of the four controllability 
classes by allocating a non-linear grading for each index. Finally, the three indices have been merged in the fault influence index $Q_{f}$, which has the same classification.

This fault classification method is generic and suitable for application to various vehicles types and drivelines, as well as other faults than the analysed faults. The boundary conditions for the controllability classes of each of the three criteria can be adapted to specific user needs.

The presented results show that faults in the electric driveline can lead to dangerous situations, especially at higher velocities. However, the effects of faults at lower speeds should not be underestimated, since faults such as a single-transistor turn-on failure lead to higher torques at lower velocities. Further, it has been found for all the analysed faults that the rear axle has a great influence on the vehicle stability. The subtle fault reactions which can occur during a three-phase balanced short circuit of the electrical machine prove that the lane keeping index is needed in addition to the vehicle stability index and collision avoidance index. The presented results are only valid for the tested medium-sized vehicle with its four in-wheel motors. In cases where only two motors are installed on the rear axle or where different motor designs are used, the faulty torque of the electrical machines can lead to higher values. This can lead to a bigger influence on the indices of vehicle stability, lane keeping and collision avoidance.

This study has established the base for a future investigation of how drivers react to the types of faults dealt with in this article. Simulator and real-life experiments will be conducted and analysed in the same way in order to validate the fault classification method. Further, a future research study will explore how fault-tolerant control can be employed to increase the controllability of road vehicles when a fault occurs.

\section{Acknowledgements}

The financial support from SHC (the Swedish Hybrid Vehicle Centre) and the Swedish Energy Agency is gratefully acknowledged. Special thanks are extended to Oskar Wallmark at the Department of Electrical Energy Conversion at the Royal Institute of Technology for the development of an electrical driveline model.

\section{References}

[1] A. Erke, Effects of electronic stability control on accidents: A review of empirical evidence, Accident Analysis \& Prevention 40 (2008), pp. 167-173.

[2] S. Ferguson, The effectiveness of electronic stability control in reducing real-world crashes: a literature review, Traffic Injury Prevention 8 (2007), pp. 329-338.

[3] H. Riener, T. Mrazek, and A. Roth, Virtual Simulation of X-by-Wire Control Systems for Commercial Vehicle with Steer-by-Wire Applications, in 5. Internationales CTI-Forum Nutzfahrzeuge, 2005.

[4] W. Bernhart and M. Valentine-Urbschat, Powertrain 2020 - The Future Drives Electric, Technical report, Roland Berger, 2009.

[5] International Energy Agency, Technology Roadmap - Electric and plug-in hybrid electric vehicles, Technical report, 2009.

[6] D. Wanner, A. Stensson Trigell, L. Drugge, and J. Jerrelind, Survey on fault-tolerant vehicle design, in 26th Electric Vehicle Symposium, 2012

[7] U. Stoll, Sensotronic Brake Control (SBC) - The electro-hydraulic brake from Mercedes-Benz, VDIBerichte 1646 (2001), pp. 825-836.

[8] C. Winkler, T. Gordon, and Z. Bareket, Engineering Assessment of Current and Future Vehicle Technologies, , University of Michigan - Transportation Research Institute (UMTRI), 2005.

[9] J. Meiners, Mercedes cancels by-wire brake system; decision a blow to technology's future; Article available on www.autoweek.com.

[10] Toyota Motor Corporation, Toyota Announces Voluntary Safety Recall of Certain 2006 and 2007 Model Year Highlander Hybrid and RX 400h Vehicles; Article available on pressroom.toyota.com/releases.

[11] N.N., Voluntary safety recall campaign 2012-2013 Altima - transverse link and power steering rack bolts; Article available on www.nhtsa.gov. 
[12] M. Euchler, T. Bonitz, M. Geyer, and D. Mitte, Evaluation of the dynamic stability of an electric driven vehicle during safety-critical situations in steady state cornering, VDI-Berichte 2086 (2009), pp. 316-333.

[13] M. Euchler, T. Bonitz, D. Mitte, and M. Geyer, Bewertung der Fahrsicherheit eines Elektrofahrzeugs bei stationärer Kreisfahrt, ATZ-Automobiltechnische Zeitschrift 112 (2010), pp. 206-213.

[14] R. Isermann and P. Ball, Trends in the application of model-based fault detection and diagnosis of technical processes, Control Engineering Practice 5 (1997), pp. 709 - 719.

[15] B.A. Welchko, T.M. Jahns, and S. Hiti, IPM synchronous machine drive response to a single-phase open circuit fault, IEEE Trans. Power Electron. 17 (2002), pp. 764-771.

[16] B.A. Welchko, T.M. Jahns, W.L. Soong, and J.M. Nagashima, IPM synchronous machine drive response to symmetrical and asymmetrical short circuit faults, IEEE Trans. Energy Conversion 18 (2003), pp. 291-298.

[17] T.M. Jahns and V. Caliskan, Uncontrolled generator operation of interior PM synchronous machines following high-speed inverter shutdown, IEEE Trans. Ind. Applicat. 35 (1997), pp. 1347-1356.

[18] Y. Liao, Analysis of fault conditions in permanent-magnet in-wheel motors, Master thesis, KTH Royal Institute of Technology, 2011.

[19] J. Liu, X. Ding, and C. Mi, Effectively dealing with uncontrolled generation of traction motors in hybrid electric vehicles, in International Conference on Electrical Machines and Systems (ICEMS), 2011.

[20] O. Wallmark, Control of Permanent-Magnet Synchronous Machines in Automotive Applications, Doctoral Thesis, Chalmers University of Technology, Gothenburg, Sweden, 2007.

[21] M. Jonasson and O. Wallmark, Stability of an electric vehicle with permanent-magnet in-wheel motors during electrical faults, World Electric Vehicle Journal 1 (2007), pp. 100-107.

[22] H. Pacejka Tyre and Vehicle Dynamics, Butterworth-Heinemann Ltd, 2002.

[23] A. Brown, S. Lapapong, K. Swanson, and S. Brennan, Modeling of Planar Vehicle Dynamics during Gradual Tire Deflation, in 22nd International Symposium on Dynamics of Vehicles on Roads and Tracks, 2011.

[24] R.B. GmbH (ed.) Kraftfahrtechnisches Taschenbuch, Vieweg, 2007.

[25] U. Hackenberg and B. Heißing, Die fahrdynamischen Leistungen des Fahrer-Fahrzeug-Systems im Straßenverkehr, ATZ-Automobiltechnische Zeitschrift 84 (1982), pp. 341-345.

[26] National-Instruments, What is the ISO 26262 Functional Safety Standard?; Article available on www.ni.com.

27] H. Otto, Lastwechselreaktion von PKW bei Kurvenfahrt, TU Braunschweig, 1987.

$28]$ P. Uys, P. Els, and M. Thoresson, Criteria for handling measurement, Journal of Terramechanics 43 (2006), pp. 43-67.

[29] S. Horiuchi, N. Yuhara, and H. Takeda, Identification of driver/vehicle multiloop properties for handling quality evaluation, in 22nd International Symposium on Dynamics of Vehicles on Roads and Tracks, 1989

[30] M. Green, " How Long Does It Take to Stop?" Methodological Analysis of Driver Perception-Brake Times, Transportation human factors 2 (2000), pp. 195-216.

[31] G. Johansson and K. Rumar, Drivers' brake reaction times, Human Factors: The Journal of the Human Factors and Ergonomics Society 13 (1971), pp. 23-27.

[32] J. Schmitt, A. Breu, M. Maurer, and B. Färber, Simulation des Bremsverhaltens in Gefahrensituationen mittels experimentell validiertem Fahrermodell, in Der Fahrer im 21. Jahrhundert, 2007.

[33] X. Ma and I. Andréasson, Driver reaction time estimation from real car following data and application in GM-type model evaluation, in Proceedings of the 85th TRB annual meeting, 2006, pp. 1-19.

[34] D.B. Fambro, R.J. Koppa, D.L. Picha, and K. Fitzpatrick, Driver perception-brake response in stopping sight distance situations, Transportation Research Record: Journal of the Transportation Research Board 1628 (1998), pp. 1-7.

[35] D.V. McGehee, E.N. Mazzae, and G.S. Baldwin, Driver reaction time in crash avoidance research: Validation of a driving simulator study on a test track, in Proceedings of the human factors and ergonomics society annual meeting, Vol. 44, 2000, pp. 3-320.

[36] H. Summala, Driver/vehicle steering response latencies, Human Factors: The Journal of the Human Factors and Ergonomics Society 23 (1981), pp. 683-692.

[37] W. Blythe, T.D. Day, and W.D. Grimes, 3-dimensional simulation of vehicle response to tire blowouts, in SAE international congress $\mathcal{E}$ exposition, 1998.

[38] M. Schmitz, M. Jagiellowicz, C. Maag, and M. Hanig, The impact of different pedal solutions for supporting efficient driving with electric vehicles, in European Conference on Human Centered Design for Intelligent Transport Systems P. V. Mora, J.-F. Pace \& L. Mendoza, Valencia, Spain, 2012, pp. $21-28$.

[39] T. Eberl, R. Sharma, R. Stroph, J. Schumann, and A. Pruckner Evaluation of interaction concepts for the longitudinal dynamics of electric vehicles - Results of study focused on driving experience, Taylor \& Francis, 2012. 
Appendix A. Complete list of fault groups

Table A1. List of all the analysed faults.

\begin{tabular}{|c|c|c|c|}
\hline $\begin{array}{l}\text { Fault } \\
\text { group }\end{array}$ & Fault description & Failure effect & Example \\
\hline FG1 & Fault in electrical machine & Negative $f_{x, i}$ & $\begin{array}{l}\text { three-phase balanced } \\
\text { short circuit }\end{array}$ \\
\hline FG2 & Fault in power electronics & Negative $f_{x, i}$ & Inverter shutdown \\
\hline FG3 & $\begin{array}{c}\text { Inverter delivers wrong } \\
\text { currents }\end{array}$ & Negative $f_{x, i}$ & $\begin{array}{l}\text { Single-transistor } \\
\text { turn-on failure }\end{array}$ \\
\hline FG4 & $\begin{array}{l}\text { Current sensor sends } \\
\text { wrong signal }\end{array}$ & Negative $f_{x, i}$ & $\begin{array}{l}\text { Current sensor } \\
\text { misalignment }\end{array}$ \\
\hline FG5 & Maximum traction torque & Increased $f_{x, i}$ & $\begin{array}{l}\text { Failure in motor } \\
\text { control }\end{array}$ \\
\hline FG6 & Pressure reduction in tyre & $\begin{array}{l}\text { Reduction in } f_{x, i}, f_{y, i}, C_{x} \\
\text { and } C_{y}\end{array}$ & Puncture \\
\hline FG7 & $\begin{array}{c}\text { Large decrease of friction } \\
\text { coeff. } \mu\end{array}$ & $\begin{array}{l}\text { Large reduction in } f_{x, i} \text { and } \\
\qquad f_{y, i}\end{array}$ & Icy road \\
\hline FG8 & Blocked wheel(s) & Maximum negative $f_{x, i}$ & Gear box failure \\
\hline FG9 & Loss of wheel & $\begin{aligned} f_{x, i} \text { and } f_{y, i} \text { vanish } \\
\text { completely }\end{aligned}$ & Fatigue of material \\
\hline FG10 & $\begin{array}{l}\text { Out-of-roundness/ wheel } \\
\text { unbalance }\end{array}$ & Fluctuation of $f_{x, i}$ and $f_{y, i}$ & Misalignment \\
\hline FG11 & Intermediate braking force & Intermed. reduction in $f_{x, i}$ & $\begin{array}{l}\text { Wheel hub bearing } \\
\text { fails }\end{array}$ \\
\hline FG12 & $\begin{array}{l}\text { High braking force on } \\
\text { wheel(s) }\end{array}$ & Large reduction in $f_{x, i}$ & Gear box malfunction \\
\hline FG13 & Free rolling tyre & No positive or negative $f_{x, i}$ & Blocked calliper \\
\hline FG14 & Steering angle zeroes out & $\begin{array}{c}\delta \text { is set to zero due to } \\
\text { aligning torque }\end{array}$ & Material failure \\
\hline FG15 & Ride height increase & $z_{w}$ increases & Active susp. failure \\
\hline FG16 & Ride height decrease & $z_{w}$ decreases & Active susp. failure \\
\hline FG17 & Soft tyre side walls & $\begin{array}{l}\text { Intermed. reduction in } C_{x} \\
\text { and } C_{y}\end{array}$ & $\begin{array}{l}\text { Tyre side wall } \\
\text { deterioration }\end{array}$ \\
\hline FG18 & $\begin{array}{l}\text { Small decrease in friction } \\
\text { coefficient } \mu\end{array}$ & $\begin{array}{l}\text { Small reduction in } f_{x, i} \text { and } \\
\qquad f_{y, i}\end{array}$ & Wet road \\
\hline FG19 & $\begin{array}{l}\text { Intermediate decrease in } \\
\text { friction coeff. } \mu\end{array}$ & $\begin{array}{l}\text { Intermed. reduction in } f_{x, i} \\
\text { and } f_{y, i}\end{array}$ & Snowy road \\
\hline FG20 & $\begin{array}{l}\text { Intermittent decrease in } \\
\text { friction coeff. } \mu\end{array}$ & $\begin{array}{l}\text { Temporarily reduced } f_{x, i} \\
\text { and } f_{y, i}\end{array}$ & Bridge entry \\
\hline FG21 & Brake force reduction & $\begin{array}{l}\text { Reduction of } f_{x, i} \text { during } \\
\text { braking }\end{array}$ & Air in brake fluid \\
\hline FG22 & Halted brake force & $\begin{array}{c}\text { Negative } f_{x, i} \text { demanded } \\
\text { after braking }\end{array}$ & Foot mat \\
\hline FG23 & Steering angle locked & $\delta$ is fixed in current position & Mechanical locking \\
\hline FG24 & Steering speed reduction & Less $\dot{\delta}$ than demanded & Control failure of EPS \\
\hline FG25 & $\begin{array}{c}\text { Full steering speed } \\
\text { inversion }\end{array}$ & $\begin{array}{c}\dot{\delta} \text { opposite to that } \\
\text { demanded }\end{array}$ & Control failure of EPS \\
\hline FG26 & $\begin{array}{c}\text { Steering speed inversion by } \\
50 \%\end{array}$ & $\begin{array}{c}\dot{\delta} \text { opposite to that } \\
\text { demanded }\end{array}$ & Control failure of EPS \\
\hline FG27 & $\begin{array}{c}\text { Reduction in spring } \\
\text { stiffness }\end{array}$ & $k_{s, i}$ decreases & Broken main spring \\
\hline FG28 & Increase in spring stiffness & $k_{s, i}$ increases & Stuck main spring \\
\hline FG29 & Loss of stabilizer stiffness & $k_{s, i}$ completely vanished & Broken stabilizer \\
\hline FG30 & $\begin{array}{c}\text { Decrease in damper } \\
\text { coefficient }\end{array}$ & $c_{s, i}$ decreases & Broken damper \\
\hline FG31 & $\begin{array}{l}\text { Increase in damper } \\
\text { coefficient }\end{array}$ & $c_{s, i}$ increases & Stuck damper \\
\hline
\end{tabular}

